\title{
Currency Regimes and the Carry Trade
}

\author{
Olivier Accominotti, Jason Cen, David Chambers, and Ian W. Marsh*
}

*Accominotti, o.accominotti@lse.ac.uk, London School of Economics and CEPR; Cen, j.cen@essex.ac.uk, Essex Business School, University of Essex; Chambers, d.chambers@jbs.cam.ac.uk, Judge Business School, Cambridge University; Marsh, i.marsh@city.ac.uk, Cass Business School, City, University of London. We thank the editor (Jennifer Conrad), the referee, Geert Bekaert, Giancarlo Corsetti, Phornchanok Cumperayot, Elroy Dimson, Will Goetzmann, Cam Harvey, Antti Ilmanen, Ron Liesching, Nikola Mirkov, Scott Murray, Carol Osler, Rich Payne, Raghu Rau, Lucio Sarno, Avanidhar Subrahmanyam, John Thanassoulis, Adrien Verdelhan, and seminar participants at Cambridge University, Cass Business School, Warwick Business School, and the Bank of England, and participants at EEA 2017, NFA 2017, the 2017 World Congress of Cliometrics, the 2017 INFINITI Conference on International Finance, the 2018 FTSE World Investment Forum, and the 2018 FMA European Conference for helpful comments and suggestions. We also thank the sponsors of the 2018 FMA European Conference for their asset pricing best paper award. We are indebted to Cambridge University's Centre for Endowment Asset Management (CEAM), Cambridge Endowment for Research in Finance (CERF), and London School of Economics' Research Infrastructure and Investment Funds (RIIF) for financial support. We are grateful to Alain Naef for research assistance. 


\begin{abstract}
This study exploits a new long-run data set of daily bid and offered exchange rates in spot and forward markets from 1919 to the present to analyze carry returns in fixed and floating currency regimes. We first find that outsized carry returns occur exclusively in the floating regime, being zero in the fixed regime. Second, we show that fixed-to-floating regime shifts are associated with negative returns to a carry strategy implemented only on floating currencies, robust to the inclusion of volatility risks. These shifts are typically characterized by global flight-to-safety events that represent bad times for carry traders.
\end{abstract}




\section{Introduction}

The carry strategy going long currencies with high interest rates and short currencies with low interest rates delivers outsized mean returns. This result is based on analysis of the post Bretton Woods era (e.g., Lustig, Roussanov, and Verdelhan (2011), Burnside, Eichenbaum, Kleshchelski, and Rebelo (2011)), a period dominated by floating currencies. Our paper exploits a new foreign exchange data set to subject the carry strategy to almost a century of currency returns and to analyze the relationship between the carry trade and currency regimes.

Our study is similar to prior long-run studies of other important stylized facts in finance: the equity risk premium, the value premium, and the underpricing of Initial Public Offerings (IPOs). Jorion and Goetzmann (1999) analyzed long-run data on non-US stock markets to show that estimates of the equity risk premium based solely on the US market were upwardly biased. Davis, Fama, and French (2000) established the robustness of the

value factor in the cross section of US stock returns going back to 1926. Finally, Chambers and Dimson (2009) showed that there was no underpricing of IPOs in the first half of the twentieth century. Equally importantly, with such a long span of data, our study also exploits the considerable variation in exchange rate regimes both over time and across currencies to analyze how carry returns behave. Hence, we are the first to examine the relationship between exchange rate regimes and carry trade returns.

Our new data set of daily bid and offered exchange rates in spot and forward markets extending from 1919 to the present is an important contribution of this paper. The year 1919 marks the dawn of modern currency trading with the emergence of a continuously traded forward market in London. Consistent with the post Bretton Woods evidence, we find that the carry trade earns positive average returns over the whole sample period. Our estimated Sharpe ratio of between 0.5 and 0.6 is only slightly lower than the 0.7 to 0.8 for 
the post Bretton Woods sample. This finding of outsized carry returns across the whole period is robust to differing portfolio weights and to the inclusion of transaction costs. Unlike certain well-known stock market anomalies, the carry anomaly in foreign exchange is one that does not seem to be disappearing over time (Jones and Pomorski (2017)).

We are not the first authors to examine carry returns out-of-sample. Doskov and Swinkels (2015) report positive excess returns over the period of 1900 to 2012 albeit at a level substantially lower than in the modern period. In contrast, we find positive excess returns in our long-run sample at a considerably higher level of economic significance. Our estimated Sharpe ratio of 0.55 is twice as large as that reported by Doskov and Swinkels and much closer to levels we observe in the modern period.

Our study also addresses the shortcomings of prior studies of carry returns out-of-sample. Doskov and Swinkels (2015) do not account for transaction costs and in the absence of forward rates rely on differences in short-term interest rates. In the latter case, forward premia are imperfectly proxied due to the heterogeneity in the credit risk, maturity, and investability of the securities used in the first half of the last century. Two short sample studies (Accominotti and Chambers (2016), Cen and Marsh (2016)) examine carry returns in the 1920s and 1930s. Both studies fail to subject their findings to any robustness tests and ignore the period of 1940 to 1975.

In contrast, this study uses a continuous, long-run sample of monthly returns incorporating forward premia and bid-ask spreads. Furthermore, the finding of outsized returns to a carry strategy is subjected to numerous robustness tests. Importantly, our use of forward premia means that we are the first to report long-run results on a carry strategy implementable in real time.

Our long sample incorporates the considerable heterogeneity in exchange rate regimes both in the cross section of currencies and across time. Therefore, a second 
important contribution of our paper is the examination of the relationship between carry trade returns and currency regimes. We exploit our data set to analyze this relationship by conditioning the return to the carry trade on the exchange rate regime of each currency pair at the beginning of each period. ${ }^{1}$ We classify any currency pair into a floating (fixed) regime based on whether its exchange rate volatility is above (below) a certain threshold. Our choice of threshold derives from a simple statistical approach based on exchange rate volatility which is similar to Shambaugh (2004). This approach identifies a large number of shifts in currency regime across our long sample and hence allows us to consider the relationship between such shifts and carry trade returns.

Our first main finding is that carry trade returns vary with exchange rate regimes. Average excess returns of the unconditional carry trade are entirely driven by returns to the carry strategy conditioned on the sample of currency pairs in the floating exchange rate regime. We term this strategy the floating carry trade. In comparison, the carry strategy conditioned on the sample of currency pairs in the fixed exchange rate regime (the fixed carry trade) generates zero returns on average. Although the carry component of fixed carry trade returns is substantial at 2\%-3\% per annum, these gains are exactly offset by losses from spot rate depreciation when fixed exchange rate regimes collapse. The absence of fixed carry trade profits may well reflect the fact that central bank intervention frequently mimics the carry trade when currencies are pegged, especially during bad times when pegs are under pressure (Fratzscher, Menkhoff, Sarno, Schmeling, and Stoehr $(2018))$.

There are four other results related to our main finding regarding the regime

\footnotetext{
${ }^{1}$ We apply the term regime to currency pairs. Thus, for example, the Swiss franc may be in a fixed regime against the euro but concurrently in a floating regime against the dollar. When referring to (near) system-wide exchange rate arrangements we use terms such as the Bretton Woods sample or era. Note that even during periods when floating (fixed) rates dominate, some currency pairs were in fixed (floating) regimes.
} 
dependence of carry returns. First, we conclude that the skewness of returns to the floating carry trade strategies in our long sample differs from the consensus view regarding skewness in the literature. In the post Bretton Woods period dominated by floating currencies, outsized carry returns display negative skewness (Menkhoff, Sarno, Schmeling, and Schrimpf (2012)) and we confirm this result in our own sample. However, when we examine skewness of floating and fixed carry returns separately in our long sample, only the unprofitable fixed carry trade displays negative return skewness due to losses arising from the collapse of currency pegs. In contrast, the return skewness of the profitable floating carry trade is not significantly different from zero. Second, we further explore the indirect relationship between floating carry returns and the fixed regime. We find that the more that either currency in a floating pair is in a pegged relationship with other currencies, the worse is the performance of the floating carry trade strategy. Third, our results regarding the regime dependence of carry returns hold not only for the base-neutral carry trade strategy but also for alternative specifications of the strategy employing different base currencies. Last, we ascertain that the variation of carry trade returns is not only related to the time series but also the cross section of exchange rate regimes across currency pairs.

We run a range of empirical tests to check the robustness of our finding regarding the importance of regime dependence for carry returns including employing alternative volatility measures to classify regimes and experimenting with different volatility thresholds. These results are detailed in the Internet Appendix.

Our second main finding is that the breakdown of currency pegs is associated with significant floating carry trade losses. We show that these losses are concentrated in the short portfolio of safe, funding currencies. The January 2015 abandonment by the Swiss National Bank of its cap on the value of the franc against the euro is an example of such a breakdown. This cap resulted in a low volatility regime where the franc was effectively 
pegged to the euro. The breakdown of this particular peg coincided with poor carry trade returns when investment currencies such as the Australian and New Zealand dollars depreciated against the pound sterling (GBP), while funding currencies such as the Japanese yen and Swiss franc appreciated, consistent with a flight-to-safety and their status as safe haven currencies (Ranaldo and Söderlind (2010)). Our regression analysis verifies that this example is representative of the floating carry trade experiencing losses on average at the time of fixed-to-floating regime changes. Furthermore, this finding is robust to using alternative regime-change indicators and to controlling for volatility risks.

In addition, we find that many of the largest drawdowns conditional on peg collapses coincide with historical events in international finance over the last century. Typically such regime shifts are associated with a flight-to-safety and represent bad times for carry traders. The outsized returns to the floating carry can be viewed as compensation for such bad times.

Our paper contributes to four sets of literature. First, we add to the risk-based explanations of outsized carry returns which suggest that countries differing in their interest rates have asymmetric exposures to global shocks (e.g., Lustig et al. (2011), Lustig, Roussanov, and Verdelhan (2014), Menkhoff et al. (2012), Dobrynskaya (2014), Lettau, Maggiori, and Weber (2014), and Christiansen, Ranaldo, and Söderlind (2011)). Such explanations are based on empirical analysis of the post Bretton Woods era. The relationship between exchange rate regimes and carry trade returns is underexplored. Our paper extends the literature by conditioning the standard carry trade strategy on both floating and fixed regimes over almost a century.

Second, we supplement an emerging literature aiming to understand the sustained profitability of the carry trade by analyzing the decomposition of carry trade returns (e.g., Koijen, Moskowitz, Pedersen, and Vrugt (2017), Hassan and Mano (2018)). By relating the variation of carry trade returns to the time series and cross section of currency regimes, we 
provide a novel way to understand the outsized carry trade return puzzle in asset pricing.

Third, our paper contributes to the literature that explains carry trade returns in terms of crash risks, rare disasters or peso problems (e.g., Brunnermeier, Nagel, and Pedersen (2008), Burnside et al. (2011), Farhi and Gabaix (2016), Farhi, Fraiberger, Ranciere, and Verdelhan (2013), Jurek (2014), and Chernov, Graveline, and Zviadadze (2018)). These empirical studies assume carry trade returns are exposed to some large unobserved negative shocks and estimate carry trade returns hedged by currency options in a relatively short sample. By contrast, in seeking to explain carry trade returns, our study makes explicit one type of large negative shock well represented in our long sample, namely, the fixed-to-floating regime shift.

Fourth, we touch upon a literature relating carry trade returns to skewness. This strategy which goes long negatively skewed investment currencies and shorts positively skewed funding currencies may earn positive mean returns since investors dislike skewness (Brunnermeier et al. (2008), Osler (2012), and Rafferty (2012)). Our results challenge this characteristic-based explanation given that, in our long sample, the profitable floating carry trade is not significantly skewed but the unprofitable fixed carry trade is significantly skewed. This finding adds to the evidence questioning the skewness-based explanation uncovered in other studies (Bekaert and Panayotov (2015), Burnside, Eichenbaum, and Rebelo (2011)).

The remainder of the paper is organized as follows. Section II describes the data. Section III presents long-run evidence on carry trade returns. Section IV examines the currency regime dependence of carry trade returns. In Section V, we document how peg collapses are associated with poor performance of the floating carry trade and a flight-to-safety by currency investors. Section VI concludes. 


\section{Data}

Our new dataset comprises daily bid and offered rates in spot and forward exchange markets from Dec. 1919 to Dec. 2017, covering 19 currencies of developed countries, namely Austria, Australia, Belgium, Canada, Denmark, France, Germany, Italy, Japan, the Netherlands, New Zealand, Norway, Portugal, Spain, Sweden, Switzerland, the United States, the United Kingdom, and the Euro zone. We use this data to estimate carry trade returns at monthly frequency before and after transaction costs, and measure monthly volatility of exchange rates using daily data.

Our start date of 1919 reflects the establishment of a forward currency market in London for the first time, together with a modern spot market based on dealings by telegraphic transfer (Accominotti and Chambers (2016)). It is in this period that London emerged as the major global center of currency trading (Atkin ((2005), pp. 40-41)). Currency speculation by both professional and retail traders increased substantially in the 1920s and the 1930s (Einzig (1937)), and both Keynes (Accominotti and Chambers) and Churchill (Clarke (2012)) could be counted among them.

We collect bid and ask quotations of spot and forward exchange rates from the Financial Times Historical Archive for the period of 1919 to 1975 and WM/Reuters via Datastream for the period of 1976 to 2017. Spot and forward rates are the last quotes of the day until 1994 when the 4 pm London fix begins. In the interwar period, reported foreign exchange quotes are the buying and selling rates at the close of business (Miller ((1929), p. 137), Phillips ((1926), p. 58)). We complement our dataset with other data sources including the Manchester Guardian, Einzig (1937), Keynes (1923), Barclays Bank International (BBI), Hai, Mark, and Wu (1997), and the Bank of England.

Restrictions on foreign exchange trading in London existed between the outbreak of

World War II (WWII) in September 1939 and the reintroduction of sterling convertibility 
for non-residents in Dec. 1958 (Atkin ((2005), pp. 101-112)). These would have substantially affected the ability of speculators to fully implement the carry trade during this time period. Consequently, whilst the results reported below cover the whole uninterrupted sample period of 1919 to 2017, we also report results excluding the period of 1939 to 1958 in the Internet Appendix. Our findings remain unchanged.

Table 1 presents descriptive statistics of our sample, including the number of monthly observations, the mean and standard deviation of log excess returns $(r x, \%$ per annum), one-month forward discounts ( $f d, \%$ per annum), appreciation rates $(-\Delta s, \%$ per annum), spot bid-ask spreads (BAS, basis points), and forward swap bid-ask spreads (BAF, basis points) for 18 exchange rates against GBP over the period of 1919 to 2017. Over the full sample period (Panel A), mean excess returns are generally small. Furthermore, there exists a cross-sectional correlation between forward discount and expected spot return in that currencies traded with a forward discount (premium) against GBP tend to depreciate (appreciate). We also report descriptive statistics for three subsamples: the interwar period (Dec. 1919 to July 1939) in Panel B, the WWII and Bretton Woods era (Aug. 1939 to July 1971) in Panel C, and the post Bretton Woods era (Aug. 1971 to Dec. 2017) in Panel D. Exchange rate volatility is generally lower for the WWII and Bretton Woods era when the fixed regime dominated than for the other two subsamples in which the floating regime prevailed.

Figure 1 graphs the coverage of our sample, which starts with 4 currencies and grows to 10 currencies by the early 1930s. These include the 9 currencies which were the most actively traded in the 1920s and 1930s cited by Einzig ((1937), p. 104) plus the Canadian dollar (CAD). The 9 currencies are the Belgian franc, the Swiss franc, the German mark, the Spanish peseta, the French franc, the GBP, the Italian lira, the Dutch guilder, and the U.S. dollar. The number then drops to 5 during WWII and begins to increase again after the war, reaching another peak in the post Bretton Woods period with 
18 currencies in the 1980s. The introduction of the euro in 1999 shrinks the sample back to the G10 currencies. $^{2}$

Although trading volumes were not published until 1986, foreign exchange market activity was substantial before then. The Bank of England estimated daily foreign exchange turnover on the London market in the 1920s as equivalent to $30 \%$ of British GDP and $20 \%$ of world trade volume on an annual basis (Accominotti and Chambers (2016)). Trading activity then declined sharply during WWII and during the first decade of Bretton Woods. Thereafter, once current account convertibility was restored in 1958, currency speculation resumed and London reemerged as the leading global center of foreign exchange trading from the 1960s onwards (Atkin ((2005), p. 120)).

\section{Long-Run Evidence on the Carry Trade}

In this section, using our long-run foreign exchange dataset, we examine the performance of the carry trade based on the following four definitions of the strategy:

- Linear weights a currency in proportion to its forward discount relative to the cross-sectional average interest rate. The weight on currency $i$ at time $t$ is given by

$$
w_{\text {Linear }, t}^{i, 1}=A_{\text {Linear }, t}\left(f d_{t}^{i, 1}-\overline{f d}_{t}^{1}\right)
$$

where $A_{\text {Linear, } t}$ is an adjustment factor that controls the investment scale to ensure that long or short positions both sum to unity in absolute value, $f d^{i, 1}$ denotes the forward discount of currency $i$ against GBP (indexed by "1"), and $\overline{f d}_{t}^{1}$ denotes the

\footnotetext{
${ }^{2}$ We exclude currencies in countries with very high inflation: the German mark from June 1922 to Oct. 1923 and the Portuguese escudo from April 1974 to Dec. 1985.
} 
average forward discount across all currencies against GBP. ${ }^{3}$

- H1-L1 invests in the currency with the highest forward discount and shorts the currency with the lowest forward discount.

- $H_{25 \%}-L_{25 \%}$ takes a long position in currencies in the top quartile ranked by the forward discount and a short position in those in the bottom quartile. Currencies are equal-weighted for the long position and the short position, respectively.

- Rank-based weights each currency in proportion to its rank in terms of its forward discount relative to the cross-sectional median rank.

We take advantage of the availability of bid-ask quotes in our data set to evaluate the effect of transaction costs on carry trade performance. To this end, we estimate the costs incurred in the trading of both the spot and forward exchanges. Our estimate of transaction costs in the spot market reduces the gross log excess return at time $t$ by

$$
\tau_{\mathrm{spot}, t}=\sum_{i}\left|w_{t}^{i, 1}-w_{t-1}^{i, 1}\right| \mathrm{BAS}_{t}^{i, 1}
$$

where $w_{t}^{i, 1}$ is the portfolio weight on currency $i$ at time $t$ and $\mathrm{BAS}_{t}^{i, 1}$ is the $\log$ bid-ask spread of the spot rate of currency $i$ against the reference currency. Note that the cost is determined by portfolio turnover, measured by $\left|w_{t}^{i, 1}-w_{t-1}^{i, 1}\right|$, and market liquidity, captured by the bid-ask spread. In addition, the net excess return realised at time $t$ (for the period from $t-1$ to $t$ ) is impacted by transaction costs incurred at the beginning and the end of the period. However, we only include the spot market transaction costs incurred at the end of each period by assuming that the investor's initial wealth at the beginning of

\footnotetext{
${ }^{3}$ The linear strategy in equation (1) is expressed in terms of currency pairs $(i, 1)$ where 1 represents the reference currency. In Appendix A we show that we can equivalently represent this weighting scheme in terms of general currency pairs $(i, j)$. This equivalence will be useful in Sections IV and V where we condition carry trade returns on the regime applicable to each currency pair $(i, j)$.
} 
each period is after transaction costs incurred at the end of the previous period. This choice has no impact on estimating the average return and evaluating long-term investment performance. Finally, we take into account transaction costs incurred at the beginning and the end of the whole sample and those incurred when a currency drops out of the sample or when a currency (re-)appears in the sample.

Similarly, our estimate of the cost in the forward swap transactions reduces the gross log excess return at time $t$ by

$$
\tau_{f w d, t}=\sum_{i}\left|w_{t-1}^{i, 1}\right| \mathrm{BAF}_{t-1}^{i, 1}
$$

where $\mathrm{BAF}_{t}^{i, 1}$ is the bid-ask spread of the log forward points of currency $i$ against the reference currency. Note that since the one-month forward swap transaction is always settled, assuming no default by either counterparty, the transaction cost is always incurred and is contracted at the beginning of each period.

Table 2 presents summary statistics for the carry trade over the whole sample period from 1919 to the present. The overall conclusion is that the carry trade generates positive returns across all four weighting schemes and also before and after transaction costs. The four carry trade strategies earn economically and statistically significant excess returns, ranging from $3.28 \%$ to $7.63 \%$ per annum, depending on the choice of portfolio weights and whether transaction costs are taken into account.

Although the choice of weighting scheme matters for the magnitude of average excess returns, the Sharpe ratio is more consistent across our four strategies, ranging between 0.51 and 0.55 before transaction costs and between 0.36 and 0.38 after transaction costs. This result is driven by the fact that strategies with extreme weights, e.g., the H1-L1 strategy, tend to deliver higher average returns but with more volatility and without actually improving the risk-return tradeoff. 
The decomposition of the excess return into the spot return and the carry component is also informative. The profits of the carry trade tend to be entirely generated from the carry component while the component due to spot exchange rate changes is not only economically very small but also statistically insignificant, even though the sign is always negative. This evidence is consistent with Koijen et al. (2017) who report based on a panel regression analysis that high-interest rate currencies neither depreciate, nor appreciate, on average. Furthermore, transaction costs matter for both return components. Transaction costs in the spot market reduce the average return by about $0.5 \%$ while transaction costs in the forward swaps, which are independent of the spot exchange, reduce the average return by about 1\%. Last but not least, we find positive (1.54) but statistically insignificant skewness in our long sample of carry returns. This finding contrasts with that of negative skewness in the post Bretton Woods period. We return to this subject below.

In the rest of the paper, we report carry trade returns employing the linear strategy. Our results are unaltered by the choice of alternative weighting schemes. Figure 2 graphs the cumulative log excess return to the linear carry trade strategy over the full sample period before and after transaction costs. The return to the carry trade exhibits substantial time-variation. Outperformance occurs in the 1920s and 1930s, and from the 1970s onwards. The intervening decades, when returns are substantially lower, coincides with the Bretton Woods era of fixed exchange rates. The next section examines the dependence of carry trade returns on currency regime in more detail.

\section{Carry Trade Conditional on Currency Regimes}

We next examine the performance of the carry trade conditional on the classification of exchange rate regime for each currency pair in our sample. At the beginning of each 
month within our full sample period, we first classify the exchange rate regime for each currency pair based on the ex ante volatility of its cross rate. Then we condition the carry trade strategy on each exchange rate regime and examine the performance of two regime-based carry trade strategies: the floating carry trade and the fixed carry trade.

\section{A. Classification of Exchange Rate Regimes}

Our sample period of almost a century can be divided into three episodes: the interwar period, the WWII and Bretton Woods era, and the post Bretton Woods era. Eichengreen (1996) provides a detailed analysis of the major developments in the international monetary system throughout all three episodes. The interwar period began with the removal of wartime capital controls in 1919 which forced European governments to float their currencies. By the end of 1927, all major currencies (except the Spanish peseta) had switched from floating to fixed exchange rates. This return to the gold standard proved short-lived as currency pegs were abandoned during the 1930s, particularly following the sterling crisis in Sept. 1931. At the Bretton Woods conference in 1944, countries agreed to maintain fixed (but adjustable) exchange rates relative to the U.S. dollar, which was itself convertible into gold. This was initially a success. However, first the GBP in the mid-1960s and then the U.S. dollar in the late 1960s and early 1970s were subject to considerable speculation as their pegs became increasingly difficult to defend. By 1973, Bretton Woods was at an end and the major currencies of the world largely persevered with floating exchange rates thereafter. The major exception was the emergence of the euro in 1999. In each of these three episodes, there was substantial cross-country heterogeneity in the choice of currency regime. Very rarely did all countries adopt the same regime.

When considering exchange rate regime classification, one approach is to use the macroeconomics-based method of Ilzetzki, Reinhart, and Rogoff (2004). However, this 
approach simply describes whether the currency of a country is fixed or floating without reference to a certain anchor. Moreover, regime classification is not possible for all currency pairs following such an approach. Given these limitations, we opt for a de facto regime classification based on exchange rate volatility, similar to Shambaugh (2004). In our main analysis, we classify exchange rate regimes using cross rate volatility $\sigma_{t}^{i, j}$ measured as an exponentially moving average of spot returns for each currency pair $(i, j)$ at time $t$, i.e., $\sigma_{t}^{i, j}=100 \times \sqrt{261} \times(1-\rho) \sum_{u=0}^{t-1} \rho^{u}\left|\Delta s_{t-u}^{i, j}\right|$, where $\rho=0.99$ is chosen such that the half-life of past exchange rate is about three months. We later check the robustness of our results using alternative volatility measures to classify exchange rate regimes.

It is worth highlighting the main advantages of our approach. First, volatility is measured without look-ahead bias and therefore can be estimated in real time. Second, we can classify the regime of any currency pair, subject to the availability of exchange rate data. Third, our volatility-based classification captures the effective regime either when currencies are locked in a multilateral fashion, or when there are occasional interventions that create a wedge between the official exchange rate status and actual exchange rate movements.

Based on the ex ante volatility measure, we classify each currency pair $(i, j)$ at time $t$ into two regimes $z$ defined as

$$
z= \begin{cases}\text { Fixed, } & \text { if } \sigma_{t}^{i, j}<V \\ \text { Floating, } & \text { if } \sigma_{t}^{i, j} \geq V\end{cases}
$$

where $V$ is the volatility threshold. For our main analysis, we choose $V=4 \%$. This choice of volatility threshold demonstrates consistency with the generally accepted classification of regimes. For example, in the first instance, the G10 exchange rates against the U.S. dollar in the post Euro period are correctly classified as floating, since the minimum volatility 
estimates in this subsample lie slightly above $4 \%$. However, if we chose a lower volatility threshold, say $2 \%$ per annum, currencies in the European Exchange Rate Mechanism (ERM) would be incorrectly classified as floating in the early 1980s.

Figure 3 graphs the time series of the fraction of currency pairs classified into fixed and floating exchange rate regimes based on a $4 \%$ threshold. The floating (fixed) regime fraction consists of all currency pairs with a volatility above (below) this threshold. The distribution of regimes is somewhat concentrated over time. The floating regime dominates in the post Bretton Woods period and the fixed regime does so in the Bretton Woods period and during WWII. The interwar period, consistent with the historical narrative, displays more regime heterogeneity.

\section{B. Regime-Dependent Carry Trade Performance}

We now condition the return to the linear carry trade strategy on the ex ante exchange rate regime. This is equivalent to a double portfolio sorting which treats the currency regime as a cross-sectional currency characteristic in addition to the interest rate differential. Because currency regime is a characteristic variable applicable to all currency pairs, we start by representing the carry trade strategy by a portfolio of all currency pairs. Formally, let the log excess return to the carry trade be

$$
r x_{t+1}^{\mathrm{CT}}=\sum_{i, j} w_{t}^{i, j} r x_{t+1}^{i, j}
$$

where the weight on each currency pair is denoted as

$$
w_{t}^{i, j}=A_{t} f d_{t}^{i, j}=A_{t}\left(f d_{t}^{i, 1}-f d_{t}^{j, 1}\right)
$$


with $A_{t}$ being an adjustment factor that alters the scale of investment, and the corresponding log excess return is defined as

$$
r x_{t+1}^{i, j}=f_{t}^{i, j}-s_{t+1}^{i, j}=f d_{t}^{i, j}-\Delta s_{t+1}^{i, j}
$$

where $f^{i, j}$ and $s^{i, j}$ are the log forward and spot exchange rates associated with currency pair $(i, j)$, respectively, and $\Delta s_{t+1}^{i, j}$ is the rate of depreciation of currency $i$ relative to currency $j$ from time $t$ to $t+1$. In Appendix A, we show that this representation is equivalent to the linear carry trade strategy in terms of exchange rates against a given reference currency indexed by ' 1 ' presented in Section III.

Our next step is to decompose the return to the carry trade into two regime-dependent strategies, i.e., the fixed carry trade and the floating carry trade as

$$
r x_{t+1}^{\mathrm{CT}}=\omega_{t}^{\text {Fixed }} r x_{t+1}^{\text {Fixed }}+\omega_{t}^{\text {Float }} r x_{t+1}^{\text {Float }}
$$

where

$$
\begin{aligned}
r x_{t+1}^{z} & =\frac{1}{\omega_{t}^{z}} \sum_{i, j} w_{t}^{i, j} r x_{t+1}^{i, j} \mathbf{I}_{t}^{i, j}(z) \\
\omega_{t}^{z} & =\frac{\sum_{i, j} \mathbf{I}_{t}^{i, j}(z)}{\sum_{i, j} 1}
\end{aligned}
$$

and $\mathbf{I}_{t}^{i, j}(z)$ is a dummy variable indicating whether currency pair $(i, j)$ at time $t$ is in regime $z \in\{$ Fixed, Float $\}$, and $\mathbf{I}^{i, i}(z) \equiv 0$ for $\forall z$. This decomposition provides an interpretation of the carry trade as a strategy that dynamically allocates portfolio weights on each regime style $z$ based on the the fraction $\omega_{t}^{z}$ in the investment universe. Note that when a certain regime, say the fixed regime, is absent from the investment universe, i.e, $\omega_{t}^{\text {Fixed }}=0$, and $\omega_{t}^{\text {Float }}=1$, the fixed-regime excess return corresponds to a missing value. Therefore, carry trade returns are totally driven by the floating regime, i.e., $r x_{t+1}^{\mathrm{CT}}=r x_{t+1}^{\mathrm{Float}}$. 
Table 3 presents summary statistics of returns to the fixed and floating carry trade strategies. The profitability of the carry trade is solely attributable to the returns of floating currency pairs. The average gross excess return to the floating carry trade is $9.38 \%$ per annum and the Sharpe ratio is 0.61 on an annualized basis. In comparison, the fixed carry trade delivers an insignificant excess return of $0.72 \%$ per annum on average and an insignificant Sharpe ratio of only 0.11 . These results and the results in the rest of the paper remain unchanged when we exclude the period of 1939 to 1958. All these results are included in the Internet Appendix.

The importance of regime for the performance of the carry trade strategy remains true when transaction costs are taken into account. The fixed carry trade generates losses of 55 basis points a year with the Sharpe ratio being -0.08 . The floating carry trade, on the other hand, earns a significantly positive excess return of $7.11 \%$ per annum on average with a significantly positive Sharpe ratio of 0.46 . Figure 4 contrasts the performance of the floating and fixed carry strategies both before and after transaction costs across the whole sample period. The time series pattern in the floating carry returns is similar to those of the unconditional carry strategy shown in Figure 2. In contrast, there is relatively little variation in fixed strategy returns.

We next consider the cross-sectional correlation between interest rate differentials and exchange rate changes by decomposing excess returns into the carry and spot return components. After transaction costs, the exchange rate of a floating currency pair with positive interest rate differentials $(+7.23 \%$ per annum) does not change significantly (-0.12\% per annum). This finding suggests that floating currency pairs approximately follow a random walk and forward rate unbiasedness is violated. The further implication is that the interest rate differential represents a risk premium.

By contrast, the high interest rate currency of a fixed currency pair tends to depreciate substantially relative to the low interest rate currency when the currency peg 
collapses. Importantly, the insignificant fixed carry trade returns do not arise from an absence of interest rate differentials for fixed currency pairs. In fact, the carry component of the fixed carry trade is statistically significant and reasonably high $(+3.13 \%$ per annum before transaction costs). However, after transaction costs, the gains from the interest rate differential $(+2.34 \%$ per annum $)$ are offset by capital losses from future spot exchange rate changes $(-2.89 \%$ per annum) in the month when the peg collapses. This finding suggests that for fixed carry trade pairs, exchange rate changes are predicted by interest differentials and that forward rate unbiasedness holds. There is no risk premium for the fixed carry trade.

We perform two checks to confirm our results on the lack of a return to the fixed carry trade. First, we check whether in countries with high yielding pegged currencies financial repression compresses their short-term interest rates and hence the interest rate differential of the carry trade. On the assumption that long bond yields are less affected by financial repression, we examine whether the magnitude of long bond yield differentials differs from the forward discount in a fixed regime. Accordingly we estimate the following regression:

$$
f d_{t}^{i, j}=-0.0002+1.11\left(y_{t, 10}^{i}-y_{t, 10}^{j}\right)-0.30\left(y_{t, 10}^{i}-y_{t, 10}^{j}\right) \mathbf{I}_{t}^{i, j}+\lambda^{i j}+\epsilon_{t}^{i, j},
$$

where $y_{t, 10}^{i}$ and $y_{t, 10}^{j}$ denote the ten-year bond yields for currencies $i$ and $j$ respectively, $\mathbf{I}_{t}^{i, j}$ is a dummy variable taking the value 1 if currency pair $(i, j)$ at time $t$ is in the fixed regime, and 0 otherwise. Coefficients are estimated from a panel regression with fixed effects $\left(\lambda^{i, j}\right)$. The statistically significant negative coefficient on the yield spread interacted with the fixed regime indicator suggests that one-month forward discounts are lower in fixed regimes than the ten-year yield spread would predict. This is consistent with the view that financial repression compresses short-term interest rate differentials. We then reconstruct the carry trade strategy after adjusting the forward discounts of fixed currency pairs using 
the results from equation (10). Even when these higher carry components are included, they are fully offset by spot rate depreciation such that there is no risk premium.

Second, we consider whether there is a short-term overshoot of the depreciating currency when a peg collapses such that spot exchange rate losses to the fixed carry trade in the month immediately following the collapse are overstated. To test this conjecture, we examine the spot returns of the fixed carry long-short portfolio, determined just prior to a peg collapse, over an extended post-collapse window of 3 months. There is no evidence to support an overshooting effect. Indeed, extending the holding period after the collapse of a peg only worsens the return to the fixed carry trade as the investment currency continues to depreciate (i.e. exchange rates undershoot following the collapse of the peg).

Our finding of a zero mean return to the fixed carry trade appears to be robust. One way to rationalize this result is to think about the types of trader on each side of the fixed carry strategy. Traders speculating against pegged currencies with weak fundamentals will short high interest rate currencies in the expectation that they will depreciate once the peg breaks. In other words, in the fixed regime, such speculators trade against carry. Correspondingly, traders seeming to trade with a carry strategy in a fixed regime are likely to be central banks attempting to support the high interest rate currency. Evidence in this regard can be found in a new study by Fratzscher et al. (2018) examining the interventions by 33 central banks beginning in 1995. Central banks trading with carry are not doing so in search of a risk premium and this perhaps explains why the fixed carry earns no risk premium.

Finally, it is natural to ask whether the markedly different performance of the floating and fixed carry strategies can be exploited by investors. The correlation between fixed and floating carry returns is low at just 0.07 . However, if traders were to pursue a long floating-strategy/short fixed-strategy, the resulting Sharpe ratio at only 0.25 is markedly inferior to that of a floating carry strategy (0.46). 


\section{Regime-Dependent Skewness}

In the post Bretton Woods period, outsized carry returns display negative skewness and are viewed as compensation for investors bearing this risk (Menkhoff et al. (2012)). Whilst we obtain a similar result of negative skewness in unconditional carry trade returns for the post Bretton Woods period (unreported), skewness for the whole sample period is not statistically significantly different from zero (Table 2).

However, when we examine skewness of fixed and floating carry returns separately,

we see a different picture (Table 3). The zero-profit fixed carry trade after transaction costs displays negative return skewness (-16.70), due to losses arising from the collapse of currency pegs. In contrast, the return skewness of the profitable floating carry trade after transaction costs is not significantly different from zero (0.30). Hence, this result casts some doubt on the skewness-based explanation for outsized carry trade returns. We return to a discussion of this finding in Section V.

\section{Indirect Effect of the Fixed Regime on Floating Carry Returns}

The evidence presented so far suggests a direct relationship between currency regimes and carry trade returns in so far as outsized carry trade returns seem to be concentrated in the floating regime. However, it is also possible that the fixed regime indirectly affects floating carry trade performance.

To explore this indirect channel, we first measure the extent to which each floating currency pair is interconnected with the fixed regime currencies. We sort floating currency pairs into three groups. The first group, Low Mix Floating, includes floating currency pairs with neither currency in the pair pegged to any other currency. The second group, Medium 
Mix Floating, includes floating currency pairs with either currency in the pair pegged to less than half of the remaining currencies. The third group, High Mix Floating, includes floating currency pairs with both currencies in the pair pegged to more than half of the remaining currencies.

Table 4 reports the excess returns, their decomposition, their second and third moments, and the Sharpe ratio for each of these three sorts on the floating carry strategy both before and after transaction costs. The Sharpe ratio of the floating carry trade before (after) transaction costs decreases from 0.66 (0.51) for the Low Mix Floating group to 0.39 (0.20) for the High Mix Floating group. Hence, we conclude that the more that either currency in a floating pair is in a pegged relationship with other currencies, the lower is the performance of the floating carry trade strategy. The poorer performance of the High Mix Floating group could reflect the incidence of spillovers from the collapse of currency pegs on the floating sample compared to the Low Mix Floating group. This is a theme we return to in Section V.

\section{E. Base Carry Trade Strategy}

So far we have shown that the correlation between interest rate differentials and expected returns is not unconditional but depends on exchange rate regimes by examining the standard dollar-neutral carry trade. Lustig et al. (2014) develop a new carry trade strategy that exploits the time-varying interest rate differential of a base currency (e.g., the U.S. dollar) relative to a basket of foreign currencies. They conclude that the base carry trade earns significant average excess return but exhibits different risk-return properties from the dollar-neutral carry trade.

Accordingly, we test whether our finding of regime dependence holds for different base currencies. The results are available from the authors. Only the floating base carry 
trade delivers outsized returns while the fixed base carry trade is not profitable, regardless of whether the base currency is the U.S. dollar, the GBP or the Deutsche mark (or Euro from 1999 onwards). Consistent with Lustig et al. (2014), we find that return to the base carry trade arises from both interest rate differentials and exchange rate changes, in contrast to the standard base-neutral carry trade which generates profits entirely from the carry component.

\section{F. The Time Series and Cross Section of Regime Dependence}

Previously we noted that the fraction of currency pairs in the floating regime is higher in the 1920s and 1930s and in the post Bretton Woods era and correspondingly lower in the Bretton Woods period and WWII (Figure 3). When viewed alongside the striking time-variation in carry trade performance graphed in Figures 2 and 4, we might conclude that the regime dependence documented above is a pure time series phenomenon. This view would be incorrect. Here, we verify that the variation of carry trade returns is also present in the cross section of exchange rate regimes.

We first note that in spite of the concentration of exchange rate regimes across time, both regimes are present in all three sub-periods. Around a half of all currency pairs are classified into the two regimes on average across the full sample period. The mean fractions are 0.42 for the fixed regime and 0.58 for the floating regime. Although the fraction of each regime varies substantially across different subsample periods, both regimes are always represented in the cross section. Moreover, there exist long time series of carry trade returns for both regimes: out of the 1176 months in our whole sample, there are 1128 months with non-missing observations for the fixed regime and 930 months with non-missing observations for the floating regime. We exploit this feature of our data to test the robustness of our finding regarding the regime dependence of carry trade returns. 
For each of our three subsamples, namely, the interwar period, the WWII and Bretton Woods period, and the post Bretton Woods period, we compute the performance of the fixed and floating carry trades. In all three subsamples, floating carry trade returns, both before and after transaction costs remain outsized and fixed carry returns are zero (Table 5). ${ }^{4}$

As an alternative approach, we model the time dimension of currency regimes by classifying each month according to whether there are more fixed currency pairs than floating ones or vice versa. Before and after transaction costs, both the excess return $(9.99 \%$ and $6.57 \%)$ and the Sharpe ratio (0.53 and 0.35$)$ of the floating carry trade remain positive even in those months where the fraction of fixed currency pairs is more than half of all currency pairs in the sample.

\section{G. Robustness}

We subject our results to a number of robustness tests. First, given that we classify exchange rate regimes based on a cross-rate volatility threshold, it could be that carry trade performance is dependent on volatility per se. We show that risk-adjusted carry returns do not increase once cross-rate volatility rises above 4\%. Second, our results remain unchanged when we adopt alternative methods of regime classification. Third, the inclusion of 19 emerging market currencies from 1983 onwards in the investment universe does not affect our findings. Last, we show in a panel regression setting that currency returns are dependent on regime. All these robustness tests are described more fully in the Internet Appendix.

\footnotetext{
${ }^{4}$ Note that the Sharpe ratio of the floating carry trade after transaction costs is much lower in the WWII and Bretton Woods period than in any other period. This is because transaction costs were especially high during the WWII and Bretton Woods period.
} 


\section{Carry Trade Returns and Currency Peg Collapses}

So far, we have identified two strategies, fixed and floating carry, with markedly different return properties. The positive risk-adjusted returns of the floating strategy contrast with the zero returns of the fixed strategy. In this section, we focus on the relationship between fixed and floating carry trade returns and exchange rate regime switches.

The importance of currency regime switches for floating carry returns is illustrated by the example on Jan. 15, 2015 of the Swiss National Bank (SNB) suddenly announcing that it would no longer support the cap on the franc's value against the euro. The impact of this announcement was a surge in the value of the Swiss franc by $21 \%$ against the euro over the following two days and a $5 \%$ loss of the floating carry trade over the following month. Figure 5 portrays all the currencies floating against GBP in our sample at the beginning of 2015. The Australian dollar and the New Zealand dollar, typically included in the floating carry trade as investment currencies, depreciated dramatically relative to safe haven currencies such as the Swiss franc and the Japanese yen which are typical funding currencies for the floating strategy. Interestingly, the U.S. dollar, another safe haven currency, also experienced a large appreciation.

This Swiss example of a fixed-to-floating regime switch is suggestive of a global flight-to-safety phenomenon. We next explore whether our data support the existence of floating carry losses around regime changes and whether they can be explained by a flight-to-safety phenomenon. Across the entire sample period of 1175 months, there are a

total of 457 (463) months where regime shifts occur with non-missing floating (fixed) carry returns - 208 (225) fixed-to-floating and 335 (324) floating-to-fixed. Accordingly, we analyze the relationship between these regime shifts and spot returns by estimating the 
following time series regression:

$$
-\Delta s_{t}^{z}=\alpha+\beta D_{t, \text { Fixed } \rightarrow \text { Float }}+\gamma D_{t, \text { Float } \rightarrow \text { Fixed }}+\varepsilon_{t},
$$

where $-\Delta s_{t}^{z}$ is the realized spot return to regime $z(z \in\{$ Float, Fixed $\})$ carry trade. $D_{t, \text { Fixed } \rightarrow \text { Float }}$ is a dummy variable indicating that from time $t-1$ to $t$ one or more currency pairs switch from the fixed regime to the floating regime. Similarly, $D_{t, \text { Float } \rightarrow \text { Fixed }}$ is a dummy variable indicating that from time $t-1$ to $t$ one or more currency pairs switch from the floating regime to the fixed regime.

Table 6, regression (1) shows that the switch of one or more currency pairs from a fixed to a floating regime is associated with a monthly loss of 116 basis points (bp) to the floating carry trade, sizable when compared with its monthly mean excess return of 59 basis points. The fixed carry trade is directly impacted with a monthly loss of 48bp (regression (2)), given that the regime shock is triggered by the collapse of one or more currency pairs in the fixed carry trade portfolio. By contrast, a switch to the fixed regime from floating does not have a significant effect on either floating or fixed carry trade returns.

There are at least two interpretations of these results. ${ }^{5}$ One hypothesis is that there are simply spillovers from collapses of fixed currency pairs that subsequently lead to floating carry losses. An alternative hypothesis is that a flight-to-safety causes floating carry trade losses when funding currencies appreciate and puts pressure on high interest rate, pegged currencies, some of which subsequently devalue. Time series analysis does not help discriminate between the two hypotheses. When we examine spot returns at a daily frequency around fixed to floating regime changes, contemporaneous correlations between fixed and floating carry returns are high but Granger causality test results are inconclusive (and available from the authors).

\footnotetext{
${ }^{5}$ We thank the referee for encouraging us to consider these results in more detail.
} 
In an attempt to further understand the dynamics underlying fixed and floating carry returns, we decompose the contributions of the long and short legs to the returns to each strategy in normal times and at the time of regime changes. The decomposition results can depend upon the choice of reference currency. However, our findings in Table 6 using the GBP as the reference currency are unchanged for the U.S. dollar (see Internet Appendix). The loss of 106bp on the floating carry trade at the time of peg collapses is primarily driven by losses of 102bp from the short leg (regression (1)). Such losses are in stark contrast to the significant gains from the short leg in periods with no regime change (32bp). Irrespective of whether there are regime changes or not, the long leg of floating carry contributes much smaller and statistically insignificant losses. Fixed carry trade losses at times of peg collapse are more evenly balanced across long and short legs (regression (2), 16bp and 32bp respectively), though only the contributions from the short portfolio are statistically significant.

These findings are consistent with a global flight-to-safety interpretation and suggest that the Swiss franc case discussed above can be generalized. In periods of fixed-to-floating regime change, the main driver of floating carry trade losses is the appreciation of safe, low interest rate currencies rather than the collapse of risky, high interest rate currencies.

Secondary sources document a series of flight-to-safety episodes in the history of international finance (Eichengreen (1996), Aldcroft and Oliver (1998), James (2012), and Reinhart and Rogoff (2011)). How well do the largest floating carry loss events in our sample correlate with such episodes? Out of the 25 largest monthly losses to the floating carry trade associated with fixed-to-floating regime shifts, we find that 20 of these coincide with key historical events. These include: the collapse of the gold exchange standard system in the 1930s; the collapse of the managed floating regimes in Europe at the outbreak of WWII; the European Monetary System crisis of 1992 to 1993; as well as the climax of the European debt crisis in May 2010. Each of these episodes was associated 
with high uncertainty on global foreign exchange markets and investor flight to safe haven currencies (see Eichengreen). Hence, outsized carry returns can be viewed as compensation for the risk to the floating carry strategy of fixed-to-floating regime shifts associated with flight-to-safety in foreign exchange markets.

Our analysis has highlighted one type of bad times for floating carry investors that feature unpleasant movements in the international financial system, namely collapses of fixed exchange rate relationships. Since market volatility has been advanced as an important explanation for carry returns, such regime shift episodes could simply be proxying bad times as periods of high volatility. Hence, we test whether fixed-to-floating regime changes remain negatively related to carry trade returns when we control for exposure to volatility risks (Table 6). We model the volatility risk of the US equity market $(\triangle \mathrm{EQV})$ and of floating currency pairs in the foreign exchange market $(\Delta \mathrm{FXV})$. The level of volatility is measured as the exponentially weighted moving average of daily returns and volatility risk is measured as the one-month first difference of volatility. The results show that whilst the floating carry trade returns are negatively correlated with volatility risks (regressions (3) and (5)), the fixed carry trade returns are not (regressions (4) and (6)). This evidence is consistent with our results in the previous section, the unprofitable fixed carry trade is not exposed to volatility risks and therefore earns no risk premium. In contrast, the profitable floating carry trade has negative exposure to volatility risks, significant at the $10 \%$ level, earning a positive risk premium. More importantly, floating carry returns remain negatively related to regime changes after controlling for volatility risks (regressions $(7)$ and $(9)) .{ }^{6}$

Finally, we return to the discussion of our skewness results. In Section IV.C we reported zero skewness of floating carry returns contrasting with negative skewness of fixed

\footnotetext{
${ }^{6}$ The Internet Appendix contains further tests that confirm the robustness of our findings regarding the relationship between regime changes and floating carry returns.
} 
carry returns. Whilst it might appear that this result is at odds with our finding that the floating carry trade incurs considerable losses when there are fixed-to-floating regime shifts, this is not the case. First, fixed-to-floating regime shifts are systematic in that all floating currency pairs with positive interest rate differentials tend to incur substantial losses in this regime-changing episode. In contrast, fixed-to-floating regime shifts contribute to fixed carry trade returns only as an idiosyncratic shock. This is because by definition only those fixed currency pairs (with positive interest rate differentials) shifting to the floating regime incur losses, while other fixed currency pairs, with their pegs maintained, are not affected. Second, in our long sample, the floating carry trade experiences large positive returns since high interest rate currencies appreciate relative to low interest rate currencies before the corresponding exchange rates are stabilized. For instance, from July to August of 1926, the French franc and the Belgian franc appreciated by $19 \%$ and $9 \%$, respectively, against the U.S. dollar prior to their return to the interwar gold standard. Such appreciations contribute to a positive excess return of $20 \%$ to the floating carry trade in that same month. These positive returns add positive skewness to floating carry returns which offsets their negatively skewed systematic component. Hence, skewness is not an appropriate statistic with which to characterize the risk of the floating and therefore the unconditional carry trade.

\section{Conclusion}

In this article, we document the long run performance of the carry trade using a new foreign exchange dataset covering the history of established currency trading from 1919 to the present. Using this database we first confirm that the carry trade generates robustly significant long run performance. This evidence is invariant across different weighting schemes for the carry trade strategy and after transaction costs are deducted. 
Our key contribution to the literature is to examine how the risk and return of the carry trade are related to currency regimes over this long run sample period. We report two main findings.

First, we find that carry trade returns are related to both the time series and cross-sectional variation of exchange rate regimes. Outsized carry trade returns can be attributed exclusively to floating currency pairs. The average annualized excess return after transaction costs is $7.11 \%$ per annum and the Sharpe ratio is 0.46 . In contrast, the fixed carry trade is not profitable. Perhaps surprisingly, the carry component of the fixed carry trade, although considerably less than that of the floating carry trade, is nonetheless a statistically significant $2 \%-3 \%$ per annum on average. However, this is fully offset by the exchange rate depreciation arising from currency peg collapses. In other words, carry strongly predicts future spot rate depreciation among fixed currency pairs. As a result of the latter, fixed carry returns are negatively skewed. Importantly, the skewness of outsized floating carry returns is insignificantly different from zero in our long sample. This result challenges the conclusion drawn from the analysis of the post Bretton Woods era that outsized carry returns represent compensation to investors for bearing negative skewness.

Second, exchange rate regime shifts offer a potential channel to explain the positive mean return to the carry trade. While a floating to fixed regime change does not affect carry returns, the breakdown of a currency peg is associated with floating carry trade losses averaging 116 basis points per month. These losses are driven by the poor performance of the short portfolio of safe funding currencies indicative of a flight-to-safety following such breakdowns. Regime changes are sometimes clustered and we also conclude that the more fixed exchange rates switch to floating, the worse the return to carry trading (even if the investment universe comprises only ex ante floating rates). We find that a large proportion of the largest monthly losses to the floating carry trade strategy at the time of 
peg collapses coincide with historical events in the financial and currency markets which are characterized by heightened uncertainty and are well documented in the secondary literature.

Robustness tests show that our characterization of currency regime shifts is not simply proxying exchange rate volatility. Consequently, we argue that the premium earned by floating carry traders is in part compensation for withstanding substantial losses at the time of peg collapses. Our explanation for the existence of a carry risk premium complements existing explanations in the literature. 


\section{Appendix A Equivalent Representations of Carry Trade Returns}

To help motivate our methodology of classifying exchange rate regimes and conditioning the carry trade on currency regimes with regard to currency pairs, we start with an alternative representation of the linear carry trade strategy, which is equivalent to the linear strategy presented in Section III.

Formally, let the log excess return to the carry trade be

$$
r x_{t+1}=\sum_{i, j} w_{t}^{i, j} r x_{t+1}^{i, j}
$$

where the weight on each individual currency pair is denoted as

$w_{t}^{i, j}=A_{t} f d_{t}^{i, j}=A_{t}\left(f d_{t}^{i, 1}-f d_{t}^{j, 1}\right)$ and where $A_{t}$ is an adjustment factor that alters the scale of investment.

We first verify that this new policy rule is indeed equivalent to the linear policy rule in terms of exchange rates against a given reference currency, indexed by "1", without loss of generality, as follows:

$$
\begin{aligned}
r x_{t+1} & =\sum_{i, j} w_{t}^{i, j} r x_{t+1}^{i, 1}-\sum_{i, j} w_{t}^{i, j} r x_{t+1}^{j, 1} \\
& =\sum_{i}\left(\sum_{j} w_{t}^{i, j}\right) r x_{t+1}^{i, 1}+\sum_{j}\left(\sum_{i} w_{t}^{j, i}\right) r x_{t+1}^{j, 1} \\
& =\sum_{i}\left(2 \sum_{j} w_{t}^{i, j}\right) r x_{t+1}^{i, 1} .
\end{aligned}
$$


Substituting in the definition of the linear weights regarding currency pairs, we obtain

$$
\begin{aligned}
r x_{t+1} & =\sum_{i}\left(\sum_{j} 2 A_{t}\left(f d_{t}^{i, 1}-f d_{t}^{j, 1}\right)\right) r x_{t+1}^{i, 1} \\
& =\sum_{i} 2 A_{t} N_{t}\left(f d_{t}^{i, 1}-\overline{f d}_{t}^{1}\right) r x_{t+1}^{i, 1} \\
& \equiv \sum_{i} w_{\text {Linear }, t}^{i, 1} r x_{t+1}^{i, 1},
\end{aligned}
$$

where $N_{t}$ is the number of currencies available in the investment universe at time $t$. The linear strategy in terms of currency pairs is equivalent to the linear strategy in terms of currencies against a fixed reference currency as long as the scaling factors are defined as $A_{t} \equiv A_{\text {Linear, }, t} /\left(2 N_{t}\right)$. Similarly, we show below that the regime-dependent carry trade strategies can be implemented by an effective weighting scheme using only exchange rates against GBP:

$$
\begin{aligned}
r x_{t+1}^{z} & =\frac{1}{\omega_{t}^{z}} \sum_{i} \sum_{j} w_{t}^{i, j} r x_{t+1}^{i, j} \mathbf{I}_{t}^{i, j}(z) \\
& =\frac{1}{\omega_{t}^{z}} \sum_{i}\left(\sum_{j} w_{t}^{i, j} \mathbf{I}_{t}^{i, j}(z)\right) r x_{t+1}^{i, 1}+\frac{1}{\omega_{t}^{z}} \sum_{j}\left(\sum_{i} w_{t}^{j, i} \mathbf{I}_{t}^{j, i}(z)\right) r x_{t+1}^{j, 1} \\
& =\frac{2}{\omega_{t}^{z}} \sum_{i}\left(\sum_{j} w_{t}^{i, j} \mathbf{I}_{t}^{i, j}(z)\right) r x_{t+1}^{i, 1} \\
& \equiv \sum_{i} w_{\mathrm{Eff}, t}^{i}(z) r x_{t+1}^{i, 1},
\end{aligned}
$$

where

$$
w_{\mathrm{Eff}, t}^{i}(z)=\frac{2}{\omega_{t}^{z}} \sum_{j} w_{t}^{i, j} \mathbf{I}_{t}^{i, j}(z)
$$

When estimating regime-dependent carry trade returns, we need to take into account transaction costs. In section III, we estimated the impact of transaction costs 
assuming linear strategy with a given reference currency. Of course, the equivalence of our new representation of the carry trade based on all currency pairs to the linear strategy representation with a given reference currency may not hold when transaction costs are taken into account. This is because the choice of the reference currency matters for the bid-ask spread and additionally because turnover rates will differ between these two representations. However, bid-ask spreads are not needed and we can implement the regime-dependent carry trade using exchange rates against GBP, recognizing equations (A.4) and (A.5):

Since the carry trade strategy conditioned on all regime $z$ currency pairs can be implemented by the effective portfolio weights $w_{\mathrm{Eff}, t}^{i}(z)$ using exchange rates against GBP, transaction costs associated with this effective weighting scheme are measured as

$$
\tau_{\mathrm{spot}, t}(z)=\sum_{i}\left|w_{\mathrm{Eff}, t}^{i}(z)-w_{\mathrm{Eff}, t-1}^{i}(z)\right| \mathrm{BAS}_{t}^{i, 1}
$$

for the spot market and

$$
\tau_{\mathrm{fwd}, t}(z)=\sum_{i}\left|w_{\mathrm{Eff}, t-1}^{i}(z)\right| \mathrm{BAF}_{t-1}^{i, 1}
$$

for the forward market.

Finally, we can define the long and short legs of the regime-dependent carry trade strategies using the GBP as the reference currency:

$$
\begin{aligned}
r x_{t+1}^{z} & =\sum_{i} w_{\mathrm{Eff}, t}^{i}(z) r x_{t+1}^{i, 1} \\
& =\underbrace{\sum_{i} w_{\mathrm{Eff}, t}^{i}(z) \mathbf{I}_{w_{\mathrm{Eff}, t}^{i}(z) \geq 0} r x_{t+1}^{i, 1}}_{\text {Long Portfolio }}+\underbrace{\sum_{i} w_{\mathrm{Eff}, t}^{i}(z) \mathbf{I}_{w_{\mathrm{Eff}, t}^{i}(z)<0} r x_{t+1}^{i, 1}}_{\text {Short Portfolio }}
\end{aligned}
$$




\section{References}

Accominotti, O.; and D. Chambers. "If You're So Smart: John Maynard Keynes and Currency Speculation in the Interwar Years." Journal of Economic History, 76 (2016), $342-386$.

Aldcroft, D. H.; and M. J. Oliver. Exchange Rate Regimes in the Twentieth Century. Cheltenham, UK: Edward Elgar (1998).

Atkin, J. The Foreign Exchange Market of London. New York, NY: Routledge (2005).

Bekaert, G.; and G. Panayotov. "Good Carry, Bad Carry." Columbia Business School Research Paper No. 15-53 (2015).

Brunnermeier, M. K.; S. Nagel; and L. H. Pedersen. "Carry Trade and Currency Crashes." NBER Macroeconomics Annual, 23 (2008), 313-347.

Burnside, C.; M. Eichenbaum; I. Kleshchelski; and S. Rebelo. "Do Peso Problems Explain the Returns to the Carry Trade?" Review of Financial Studies, 24 (2011), 853-891.

Burnside, C.; M. Eichenbaum; and S. Rebelo. "Carry Trade and Momentum in Currency Markets." Annual Review of Financial Economics, 3 (2011), 511-535.

Cen, J.; and I. W. Marsh. "Foreign Exchange Trading Strategies and Rare Events." Working Paper, Cass Business School (2016).

Chambers, D.; and E. Dimson. "IPO Underpricing over the Very Long Run." Journal of Finance, 64 (2009), 1407-1443.

Chernov, M.; J. Graveline; and I. Zviadadze. "Crash Risk in Currency Returns." Journal of Financial and Quantitative Analysis, 53 (2018), 137-170. 
Christiansen, C.; A. Ranaldo; and P. Söderlind. "The Time-Varying Systematic Risk of Carry Trade Strategies." Journal of Financial and Quantitative Analysis, 46 (2011), $1107-1125$.

Clarke, P. Mr Churchill's Profession: Statesman, Orator, Writer. London, Berlin, New York, Sydney: Bloomsbury (2012).

Davis, J.; E. F. Fama; and K. French. "Characteristics, Covariances and Average Returns: 1929 to 1997." Journal of Finance, 55 (2000), 389-406.

Dobrynskaya, V. "Downside Market Risk of Carry Trades." Review of Finance, 18 (2014), $1885-1913$.

Doskov, N.; and L. Swinkels. "Empirical Evidence on the Currency Carry Trade, 1900-2012." Journal of International Money and Finance, 51 (2015), 370-389.

Eichengreen, B. Globalizing Capital: A History of the International Monetary System. Princeton, NJ: Princeton University Press (1996).

Einzig, P. The Theory of Forward Exchange. London, UK: MacMillan (1937).

Farhi, E.; S. Fraiberger; R. Ranciere; and A. Verdelhan. "Crash Risk in Currency Markets." Working Paper, Harvard University (2013).

Farhi, E.; and X. Gabaix. "Rare Disasters and Exchange Rates." The Quarterly Journal of Economics, 131 (2016), 1-52.

Fratzscher, M.; L. Menkhoff; L. Sarno; M. Schmeling; and T. Stoehr. "Systematic Intervention and Currency Risk Premia." Working Paper, Cass Business School (2018).

Hai, W.; N. C. Mark; and Y. Wu. "Understanding Spot and Forward Exchange Rate Regressions." Journal of Applied Econometrics, 12 (1997), 715-734. 
Hassan, T. A.; and R. C. Mano. "Forward and Spot Exchange Rates in a Multi-Currency World." Quarterly Journal of Economcis, 134 (2018), 397-450.

Ilzetzki, E. O.; C. M. Reinhart; and K. S. Rogoff. "Exchange Rate Arrangements into the 21st Century: Will the Anchor Currency Hold?" Unpublished (2004).

James, H. Making the European Monetary Union. Cambridge, MA: Harvard University Press (2012).

Jones, C. S.; and L. Pomorski. "Investing in Disappearing Anomalies." Review of Finance, 21 (2017), 237-267.

Jorion, P.; and W. N. Goetzmann. "Global Stock Markets in the Twentieth Century." Journal of Finance, 54 (1999), 953-980.

Jurek, J. W. "Crash-Neutral Currency Carry Trades." Journal of Financial Economics, 113 (2014), 325-347.

Keynes, J. M. A Tract on Monetary Reform. London, UK: Macmillan (1923).

Koijen, R. S.; T. J. Moskowitz; L. H. Pedersen; and E. B. Vrugt. "Carry." Journal of Financial Economics, 127 (2017), 197-225.

Lettau, M.; M. Maggiori; and M. Weber. "Conditional Risk Premia in Currency Markets and Other Asset Classes." Journal of Financial Economics, 114 (2014), 197-225.

Lustig, H.; N. Roussanov; and A. Verdelhan. "Common Risk Factors in Currency Markets." Review of Financial Studies, 24 (2011), 3731-3777.

Lustig, H.; N. Roussanov; and A. Verdelhan. "Countercyclical Currency Risk Premia." Journal of Financial Economics, 111 (2014), 527-553.

Menkhoff, L.; L. Sarno; M. Schmeling; and A. Schrimpf. "Carry Trades and Global Foreign Exchange Volatility." Journal of Finance, 67 (2012), 681-718. 
Miller, H. F. R. The Foreign Exchange Market: A Practical Treatise on Post-War Foreign Exchange. 2nd ed. London, UK: E. Arnold (1929).

Osler, C. L. "Market Microstructure and the Profitability of Currency Trading." Annual Review of Finance and Economics, 4 (2012), 469-495.

Phillips, H. W. Modern Foreign Exchange and Foreign Banking. London, UK: Macdonald and Evans (1926).

Rafferty, B. "Currency Returns, Skewness and Crash Risk." Working Paper, University of Melbourne (2012).

Ranaldo, A.; and P. Söderlind. "Safe Haven Currencies." Review of Finance, 14 (2010), $385-407$.

Reinhart, C. M.; and K. S. Rogoff. "From Financial Crash to Debt Crisis." American Economic Review, 101 (2011), 1676-1706.

Shambaugh, J. "The Effects of Fixed Exchange Rates on Monetary Policy." Quarterly Journal of Economcis, 119 (2004), 301-352. 
FIGURE 1

\section{Sample Coverage}

Figure 1 graphs the number of currencies in the investment universe that are used to construct the carry trade strategy over the period Dec. 1919 to Dec. 2017. Time is indexed as of the portfolio formation date.

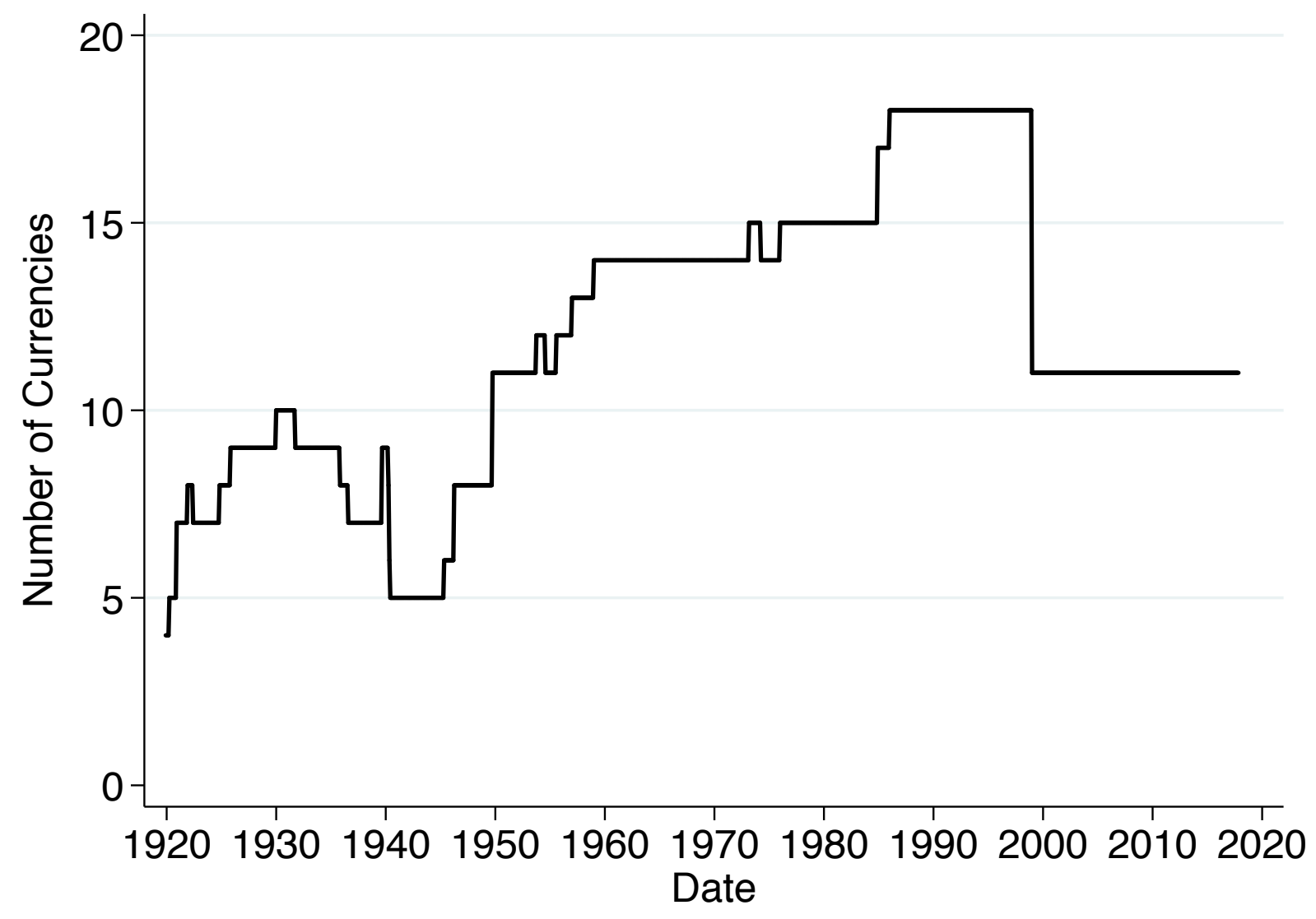


FIGURE 2

\section{Long-Run Carry Trade Returns}

Figure 2 graphs the cumulative log excess return to the carry trade strategy from Dec. 1919 to Dec. 2017. The solid line indicates the return before transaction costs (T.C.) and the dashed line indicates the return after transaction costs.

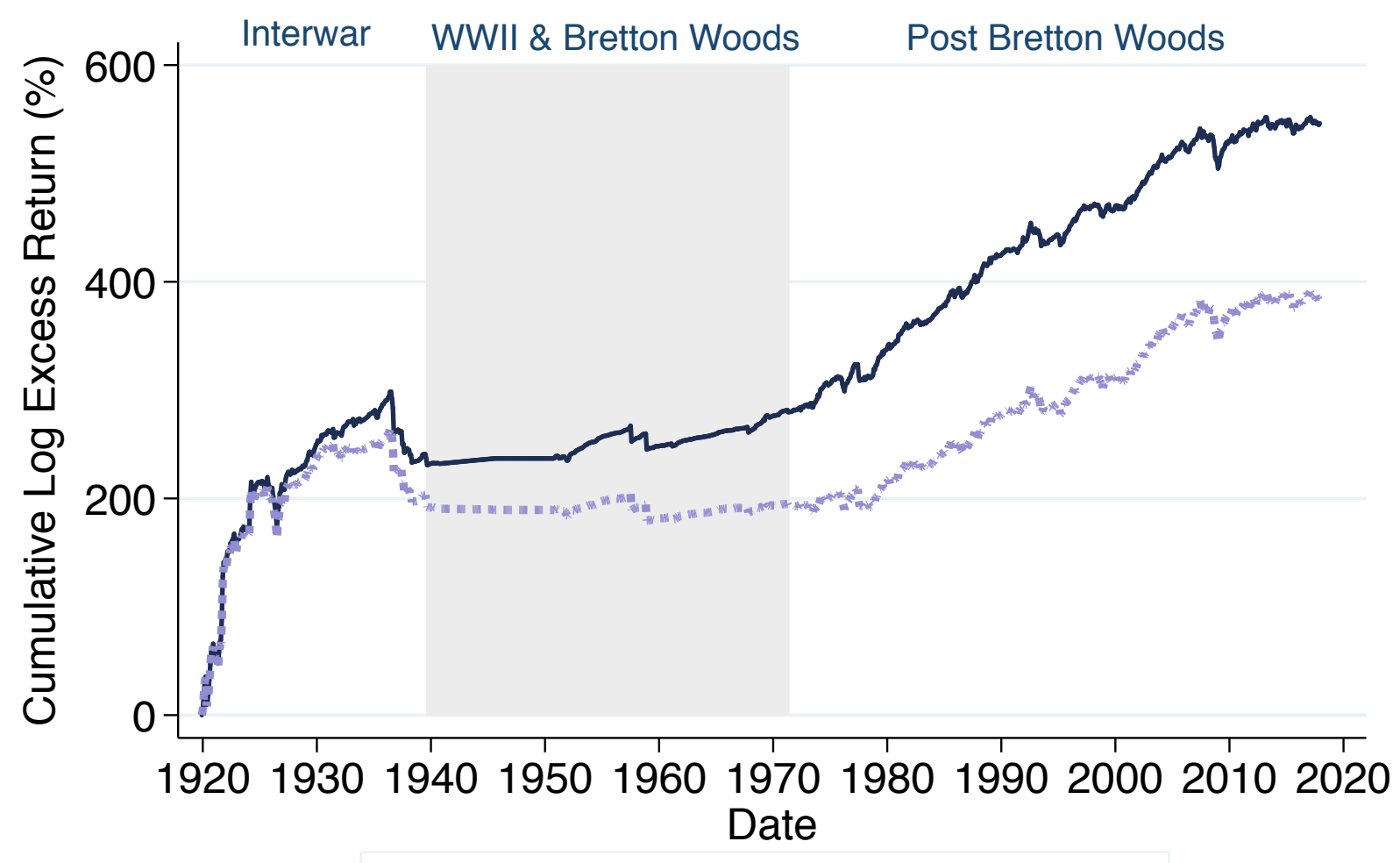

- Before T.C. 
FIGURE 3

Fraction of Currency Pairs in Each of the Fixed and Floating Regimes

Figure 3 describes the fraction of currency pairs in the investment universe that are classified in each exchange rate regime based on a volatility threshold of $4 \%$ per annum over the period Dec. 1919 to Dec. 2017.

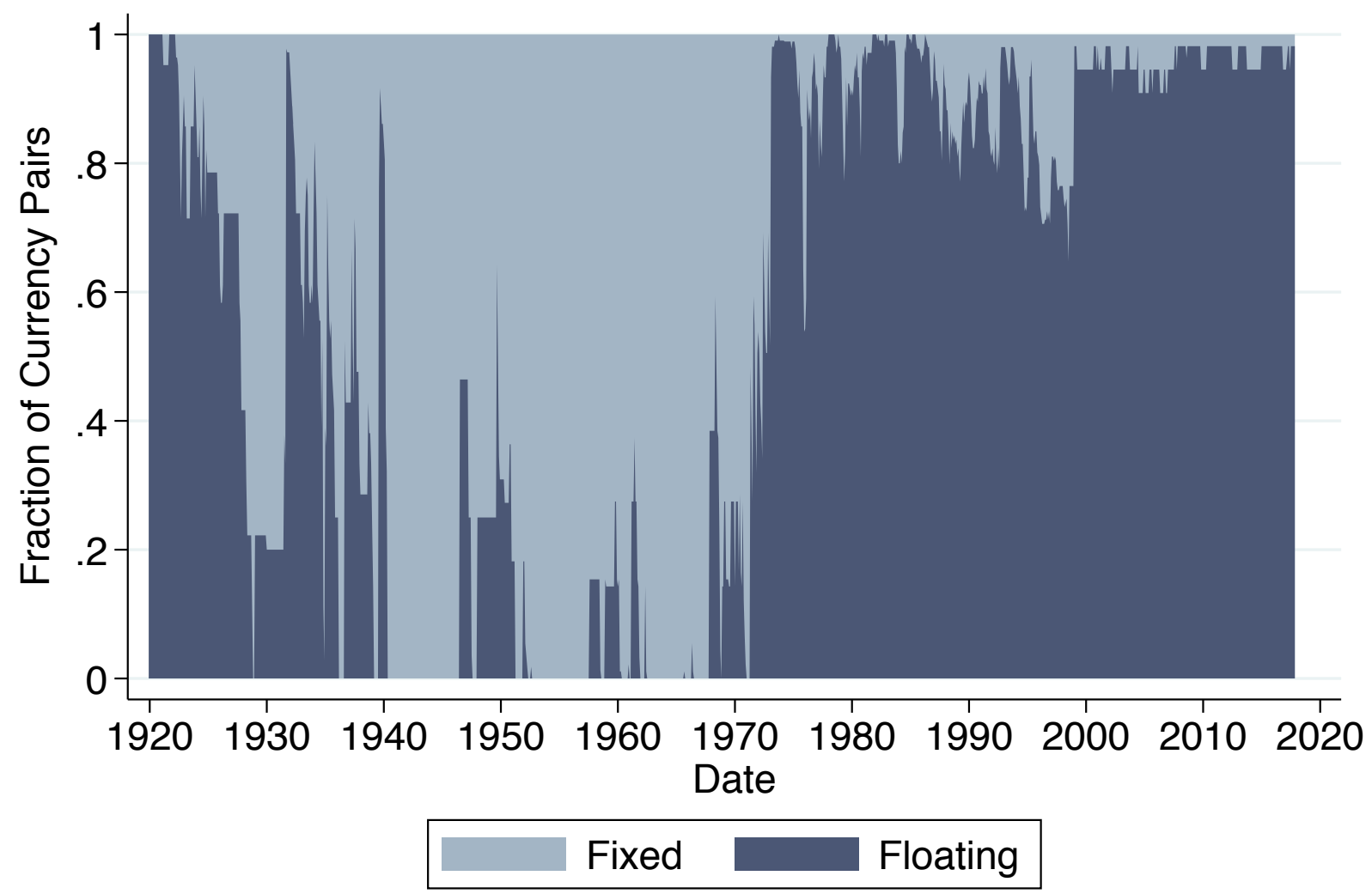




\section{FIGURE 4}

\section{Cumulative Log Excess Returns for the Floating and Fixed Carry Strategies}

Figure 4 plots the cumulative log excess returns before transaction costs (Graph A) and after transaction costs (Graph B) for the floating carry strategy (solid line) and the fixed carry strategy (dashed line) over the period Dec. 1919 to Dec. 2017.

Graph A. Before Transaction Costs

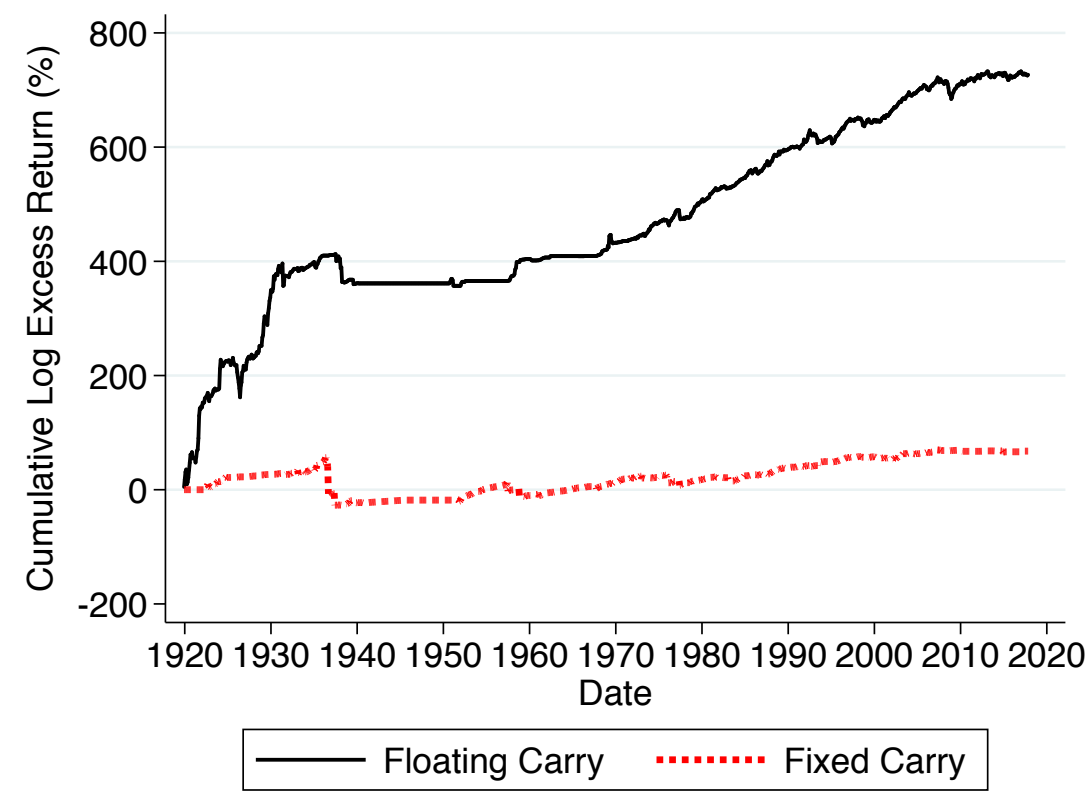

Graph B. After Transaction Costs

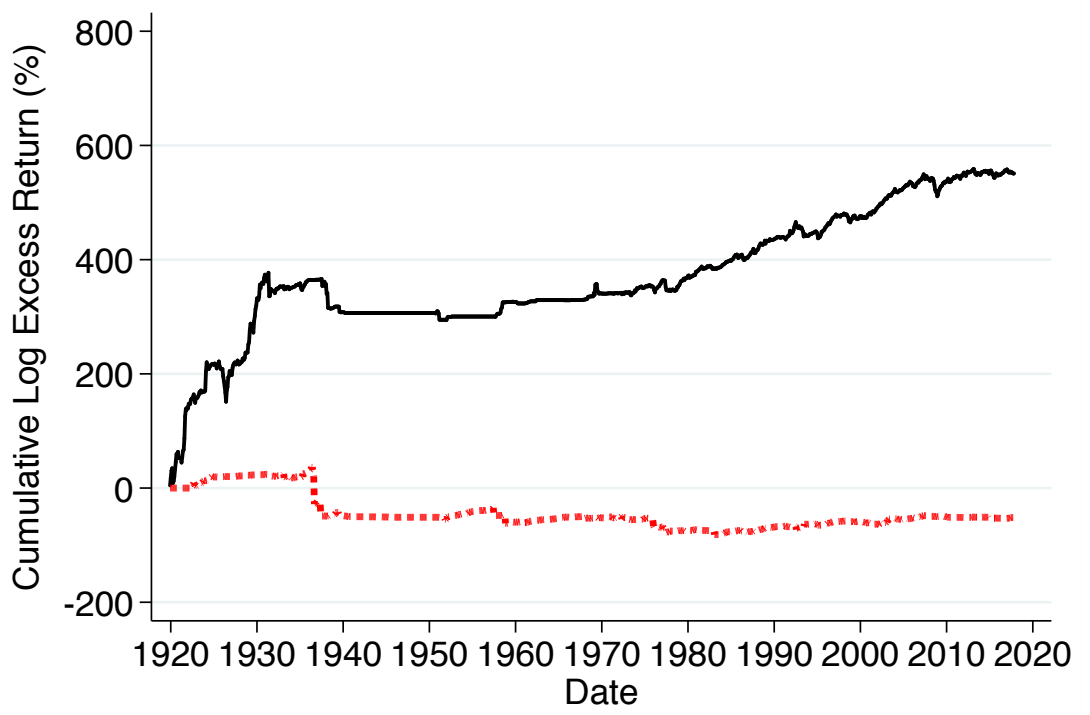

Floating Carry ......... Fixed Carry 
FIGURE 5

\section{Case Study: Switzerland Abandons Euro Cap}

Figure 5 is a scatter plot of the realized spot return against the forward discount of all currencies (the Australian dollar (AUD), the Canadian dollar (CAD), the Swiss franc (CHF), the euro (EUR), the Japanese yen (JPY), the Norwegian krone (NOK), the New Zealand dollar (NZD), the Swedish krona (SEK), and the U.S. dollar (USD)) in our investment universe floating against GBP in Jan. 2015. In that month, the Swiss National Bank announced that it could no longer support the cap on the value of CHF against EUR.

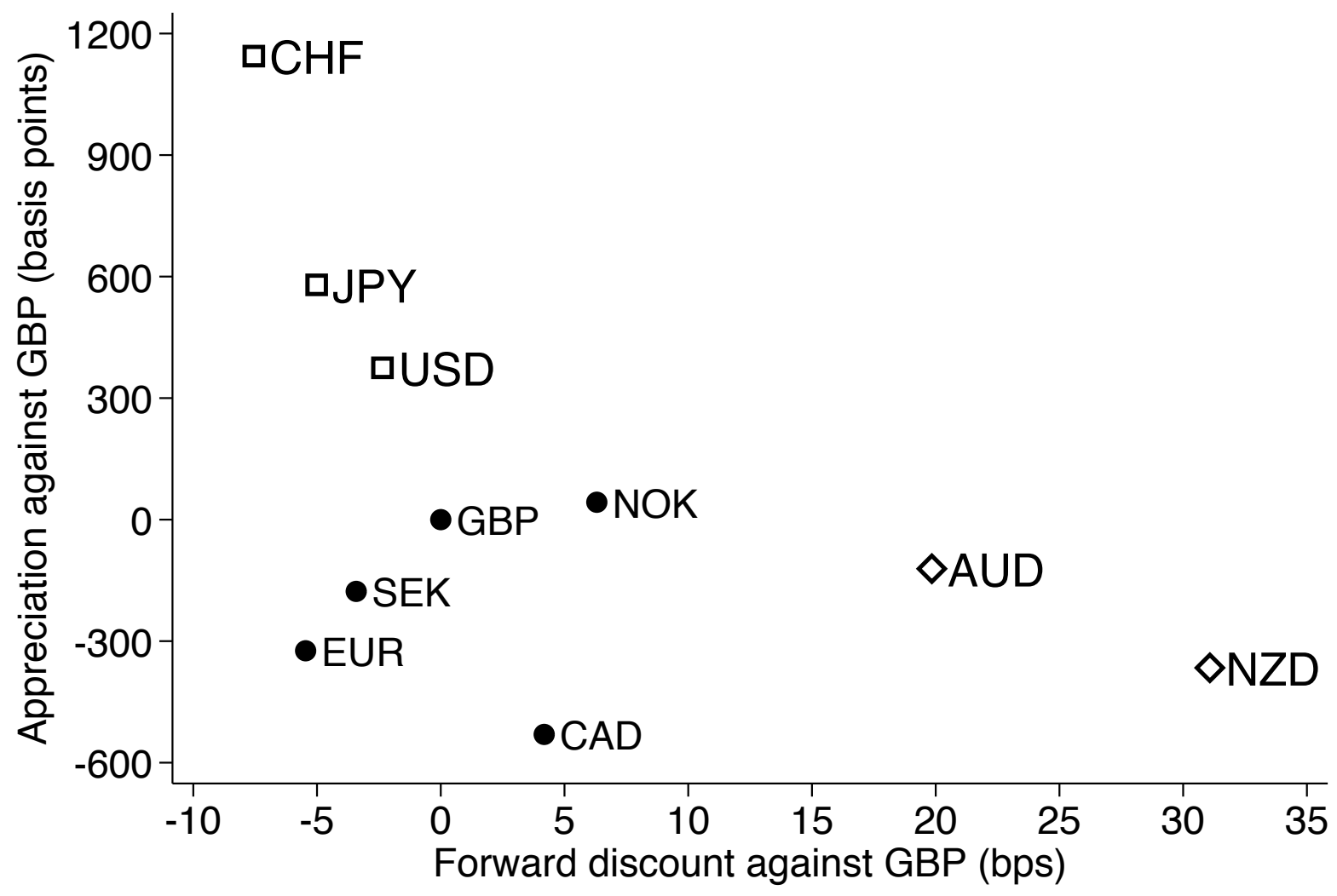




\section{TABLE 1}

\section{Sample Descriptive Statistics}

Table 1 reports the number of monthly observations, the mean and standard deviation (SD) of log excess returns (EXRET, \% per annum), carry components (CARRY, \% per annum), exchange rate returns (SPOT, \% per annum), spot bid-ask spreads (BAS, basis points), and forward swap bid-ask spreads (BAF, basis points) for 18 exchange rates against GBP over the period from Dec. 1919 to Dec. 2017. Panel A reports descriptive statistics for the full sample period, Panel B for the interwar period (Dec. 1919 to July 1939), Panel C for the WWII and Bretton Woods era (Aug. 1939 to July 1971), and Panel D for the post Bretton Woods era (Aug. 1971 to Dec. 2017).

Panel A. Full Sample

\begin{tabular}{lrrrrrrrrrrr}
\hline & \multicolumn{4}{c}{ EXRET } & \multicolumn{2}{c}{ CARRY } & \multicolumn{2}{c}{ SPOT } & \multicolumn{2}{c}{ BAS } & \multicolumn{2}{c}{ BAF } \\
\cline { 2 - 11 } Country & obs & Mean & SD & Mean & SD & Mean & SD & Mean & SD & Mean & SD \\
\hline Australia & 396 & 0.66 & 12.74 & 1.30 & 0.66 & -0.63 & 12.64 & 10 & 5 & 3 & 5 \\
Austria & 504 & -0.05 & 8.02 & -3.14 & 0.95 & 3.09 & 7.96 & 20 & 25 & 25 & 30 \\
Belgium & 877 & -0.38 & 11.01 & -0.88 & 1.22 & 0.50 & 10.95 & 13 & 13 & 11 & 11 \\
Canada & 1055 & 0.35 & 8.69 & -0.86 & 0.58 & 1.21 & 8.60 & 14 & 23 & 6 & 5 \\
Denmark & 818 & 0.96 & 7.47 & -0.27 & 0.83 & 1.23 & 7.36 & 7 & 6 & 10 & 12 \\
Euro & 227 & 0.26 & 8.39 & -1.06 & 0.25 & 1.32 & 8.38 & 6 & 2 & 1 & 1 \\
France & 879 & -1.75 & 14.44 & 1.17 & 2.12 & -2.92 & 14.66 & 9 & 8 & 10 & 10 \\
Germany & 652 & -3.93 & 15.50 & -3.15 & 1.04 & -0.78 & 15.40 & 15 & 21 & 8 & 11 \\
Italy & 712 & 0.57 & 11.76 & 1.69 & 1.60 & -1.12 & 11.52 & 10 & 12 & 14 & 17 \\
Japan & 537 & -0.56 & 12.40 & -3.83 & 1.46 & 3.27 & 12.34 & 22 & 18 & 4 & 4 \\
Netherlands & 866 & 0.34 & 7.52 & -1.89 & 0.95 & 2.23 & 7.45 & 14 & 15 & 9 & 8 \\
NewZealand & 396 & 3.11 & 12.52 & 2.38 & 1.14 & 0.74 & 12.51 & 15 & 11 & 5 & 12 \\
Norway & 825 & 0.65 & 7.54 & -0.20 & 0.86 & 0.85 & 7.47 & 9 & 9 & 9 & 11 \\
Portugal & 397 & 1.05 & 6.58 & 0.70 & 1.26 & 0.35 & 6.60 & 31 & 24 & 30 & 33 \\
Spain & 405 & 1.44 & 12.02 & 4.02 & 1.99 & -2.58 & 11.98 & 16 & 12 & 20 & 23 \\
Sweden & 939 & 0.07 & 7.43 & -0.46 & 0.86 & 0.54 & 7.40 & 14 & 16 & 9 & 10 \\
Switzerland & 1152 & 0.16 & 9.55 & -2.75 & 1.05 & 2.91 & 9.49 & 17 & 20 & 8 & 11 \\
USA & 1176 & -0.17 & 9.08 & -1.21 & 0.68 & 1.04 & 9.04 & 7 & 7 & 5 & 6 \\
\hline
\end{tabular}


TABLE 1

Sample Descriptive Statistics (cont.)

Panel B. Interwar Period (Dec. 1919 to July 1939)

\begin{tabular}{|c|c|c|c|c|c|c|c|c|c|c|c|}
\hline \multirow[b]{2}{*}{ Country } & \multicolumn{3}{|c|}{ EXRET } & \multicolumn{2}{|c|}{ CARRY } & \multicolumn{2}{|c|}{ SPOT } & \multicolumn{2}{|c|}{ BAS } & \multicolumn{2}{|c|}{ BAF } \\
\hline & obs & Mean & SD & Mean & SD & Mean & SD & Mean & SD & Mean & $\mathrm{SD}$ \\
\hline Belgium & 224 & -3.19 & 17.50 & 1.06 & 1.74 & -4.24 & 17.47 & 11 & 17 & 7 & 11 \\
\hline Canada & 115 & 1.58 & 7.12 & 0.37 & 0.26 & 1.21 & 7.15 & 14 & 19 & 7 & 3 \\
\hline France & 236 & -3.33 & 20.37 & 4.04 & 3.39 & -7.37 & 20.92 & 9 & 7 & 7 & 8 \\
\hline Germany & 109 & -20.39 & 33.37 & -0.09 & 1.03 & -20.30 & 32.98 & 19 & 38 & 7 & 7 \\
\hline Italy & 191 & 0.95 & 18.86 & 2.12 & 2.11 & -1.18 & 18.54 & 20 & 19 & 14 & 19 \\
\hline Netherlands & 224 & 2.74 & 8.78 & 0.90 & 1.00 & 1.84 & 8.77 & 10 & 18 & 6 & 7 \\
\hline Spain & 129 & 1.59 & 16.10 & 3.34 & 2.13 & -1.75 & 15.85 & 19 & 17 & 21 & 22 \\
\hline Switzerland & 212 & 1.26 & 11.21 & 0.49 & 1.08 & 0.77 & 11.21 & 11 & 20 & 6 & 10 \\
\hline USA & 236 & -0.3 & 9.49 & 0.37 & 0.47 & -0.67 & 9.56 & 6 & 7 & 2 & 2 \\
\hline
\end{tabular}

Panel C. WWII and Bretton Woods Era (Aug. 1939 to July 1971)

\begin{tabular}{lrrrrrrrrrrr}
\hline & \multicolumn{4}{c}{ EXRET } & \multicolumn{2}{c}{ CARRY } & \multicolumn{3}{c}{ SPOT } & \multicolumn{3}{c}{ BAS } & \multicolumn{2}{c}{ BAF } \\
\cline { 2 - 12 } Country & obs & Mean & SD & Mean & SD & Mean & SD & Mean & SD & Mean & SD \\
\hline Austria & 175 & -0.17 & 3.87 & -1.5 & 0.57 & 1.33 & 3.87 & 7 & 4 & 26 & 22 \\
Belgium & 324 & 0.35 & 5.43 & -1.32 & 0.64 & 1.67 & 5.37 & 9 & 12 & 10 & 9 \\
Canada & 384 & 0.95 & 6.05 & -0.82 & 0.44 & 1.77 & 6.00 & 24 & 33 & 9 & 5 \\
Denmark & 262 & 0.28 & 1.62 & -0.02 & 0.48 & 0.30 & 1.56 & 4 & 6 & 15 & 14 \\
France & 314 & -3.07 & 13.57 & 0.93 & 1.20 & -3.99 & 13.65 & 7 & 8 & 14 & 12 \\
Germany & 214 & -0.41 & 3.99 & -2.31 & 0.80 & 1.90 & 3.99 & 3 & 4 & 5 & 3 \\
Italy & 192 & -0.20 & 3.63 & -1.09 & 0.75 & 0.89 & 3.53 & 3 & 1 & 11 & 13 \\
Netherlands & 313 & -0.57 & 3.31 & -1.69 & 0.56 & 1.12 & 3.27 & 9 & 14 & 9 & 7 \\
Norway & 269 & 0.15 & 3.05 & -0.55 & 0.33 & 0.70 & 3.04 & 6 & 14 & 13 & 13 \\
Portugal & 209 & 1.18 & 4.32 & -0.33 & 0.69 & 1.52 & 4.27 & 22 & 12 & 32 & 29 \\
Sweden & 383 & 0.14 & 3.76 & -0.80 & 0.41 & 0.94 & 3.74 & 18 & 24 & 12 & 8 \\
Switzerland & 384 & 0.23 & 7.04 & -1.82 & 0.57 & 2.05 & 7.01 & 17 & 23 & 10 & 7 \\
USA & 384 & 0.49 & 7.03 & -1.26 & 0.41 & 1.74 & 7.00 & 11 & 9 & 10 & 7 \\
\hline
\end{tabular}


TABLE 1

Sample Descriptive Statistics (cont.)

Panel D. Post Bretton Woods Era (Aug. 1971 to Dec. 2017)

\begin{tabular}{lrrrrrrrrrrrr}
\hline & \multicolumn{4}{c}{ EXRET } & \multicolumn{3}{c}{ CARRY } & \multicolumn{3}{c}{ SPOT } & \multicolumn{3}{c}{ BAS } \\
\cline { 2 - 11 } Country & obs & Mean & SD & Mean & SD & Mean & SD & Mean & SD & Mean & SD \\
\hline Australia & 396 & 0.66 & 12.74 & 1.30 & 0.66 & -0.63 & 12.64 & 10 & 5 & 3 & 5 \\
Austria & 329 & 0.01 & 9.52 & -4.02 & 1.01 & 4.02 & 9.44 & 27 & 29 & 24 & 34 \\
Belgium & 329 & 0.82 & 9.26 & -1.77 & 1.12 & 2.59 & 9.09 & 17 & 7 & 14 & 11 \\
Canada & 556 & -0.32 & 10.37 & -1.14 & 0.68 & 0.82 & 10.25 & 7 & 5 & 3 & 5 \\
Denmark & 556 & 1.28 & 8.99 & -0.38 & 0.95 & 1.66 & 8.86 & 8 & 5 & 8 & 9 \\
Euro & 227 & 0.26 & 8.39 & -1.06 & 0.25 & 1.32 & 8.38 & 6 & 2 & 1 & 1 \\
France & 329 & 0.65 & 9.20 & -0.65 & 1.27 & 1.30 & 9.01 & 11 & 7 & 9 & 10 \\
Germany & 329 & -0.77 & 9.53 & -4.71 & 0.93 & 3.94 & 9.45 & 21 & 16 & 11 & 14 \\
Italy & 329 & 0.81 & 9.27 & 3.07 & 1.45 & -2.26 & 8.99 & 9 & 6 & 17 & 16 \\
Japan & 537 & -0.56 & 12.40 & -3.83 & 1.46 & 3.27 & 12.34 & 22 & 18 & 4 & 4 \\
Netherlands & 329 & -0.42 & 9.27 & -3.98 & 0.78 & 3.56 & 9.14 & 22 & 9 & 11 & 8 \\
NewZealand & 396 & 3.11 & 12.52 & 2.38 & 1.14 & 0.74 & 12.51 & 15 & 11 & 5 & 12 \\
Norway & 556 & 0.89 & 8.94 & -0.03 & 1.02 & 0.92 & 8.86 & 11 & 5 & 7 & 9 \\
Portugal & 188 & 0.90 & 8.42 & 1.84 & 1.61 & -0.94 & 8.47 & 40 & 30 & 27 & 36 \\
Spain & 276 & 1.37 & 9.57 & 4.35 & 1.91 & -2.97 & 9.69 & 14 & 8 & 20 & 24 \\
Sweden & 556 & 0.03 & 9.14 & -0.23 & 1.06 & 0.26 & 9.10 & 11 & 4 & 7 & 10 \\
Switzerland & 556 & -0.31 & 10.35 & -4.64 & 0.97 & 4.33 & 10.24 & 20 & 17 & 8 & 13 \\
USA & 556 & -0.56 & 10.12 & -1.84 & 0.79 & 1.29 & 10.01 & 5 & 5 & 2 & 2 \\
\hline
\end{tabular}


TABLE 2

\section{Long-Run Performance of the Carry Trade Before and After Transaction Costs}

Table 2 reports descriptive statistics for the annualized return to the carry trade strategies based on different weighting schemes including: (i) Linear weights a currency in proportion to its forward discount relative to the cross-sectional average interest rate; (ii) H1-L1 invests in the currency with the highest forward discount and shorts the currency with the lowest forward discount; (iii) $H_{25 \%}-L_{25 \%}$ takes a long position in currencies in the top quartile ranked by the forward discount and a short position in those in the bottom quartile; and (iv) Rank weights each currency in proportion to its rank in terms of its forward discount relative to the cross-sectional median rank. For each policy rule, we report the mean of log excess returns (EXRET, \% per annum), carry components (CARRY, \% per annum), and exchange rate returns (SPOT, \% per annum), standard deviation (SD, \% per annum) and skewness (SKEW) of log excess returns, and the Sharpe ratio (SR, annualized), both before and after transaction costs, as well as correlation (CORR) with returns to the linearly weighted strategy. Standard errors, obtained by bootstrapping under the assumption of independent and identically distributed (IID) returns, are shown in parentheses. The sample runs from Dec. 1919 to Dec. 2017.

\begin{tabular}{|c|c|c|c|c|c|c|c|c|c|c|c|c|c|}
\hline & \multicolumn{6}{|c|}{ Before Transaction Costs } & \multicolumn{7}{|c|}{ After Transaction Costs } \\
\hline & EXRET & CARRY & SPOT & SD & SKEW & SR & EXRET & CARRY & SPOT & SD & SKEW & SR & CORR \\
\hline \multirow[t]{2}{*}{ Linear } & 5.57 & 6.41 & -0.84 & 10.72 & 1.54 & 0.52 & 3.91 & 5.26 & -1.35 & 10.73 & 1.50 & 0.36 & \\
\hline & $(1.28)$ & $(0.34)$ & $(1.33)$ & $(0.97)$ & $(1.60)$ & $(0.10)$ & $(1.28)$ & $(0.30)$ & $(1.33)$ & $(0.97)$ & $(1.59)$ & $(0.10)$ & \\
\hline \multirow[t]{2}{*}{$H 1-L 1$} & 7.63 & 8.76 & -1.13 & 15.03 & 0.67 & 0.51 & 5.38 & 7.43 & -2.06 & 15.05 & 0.64 & 0.36 & 0.89 \\
\hline & $(1.72)$ & $(0.45)$ & $(1.76)$ & $(0.98)$ & $(0.89)$ & $(0.10)$ & (1.73) & $(0.40)$ & $(1.76)$ & $(0.98)$ & $(0.89)$ & $(0.10)$ & $(0.01)$ \\
\hline \multirow[t]{2}{*}{$H_{25 \%}-L_{25 \%}$} & 5.02 & 5.48 & -0.45 & 9.31 & 1.05 & 0.54 & 3.54 & 4.42 & -0.88 & 9.35 & 1.03 & 0.38 & 0.91 \\
\hline & $(1.06)$ & $(0.27)$ & (1.08) & $(0.63)$ & $(0.83)$ & $(0.10)$ & (1.07) & $(0.24)$ & $(1.09)$ & $(0.63)$ & $(0.83)$ & $(0.10)$ & $(0.01)$ \\
\hline \multirow[t]{2}{*}{ Rank } & 4.76 & 5.16 & -0.40 & 8.71 & 0.81 & 0.55 & 3.28 & 4.12 & -0.84 & 8.74 & 0.79 & 0.38 & 0.94 \\
\hline & (1.03) & $(0.25)$ & $(1.05)$ & $(0.65)$ & (1.08) & $(0.10)$ & (1.04) & $(0.22)$ & $(1.06)$ & $(0.65)$ & $(1.07)$ & $(0.10)$ & $(0.01)$ \\
\hline
\end{tabular}


TABLE 3

\section{Performance of the Fixed and Floating Carry Trades}

Table 3 reports descriptive statistics for the annualized return to the floating and fixed carry trades. A currency pair is classified as in a fixed regime if its ex ante volatility is below $4 \%$ per annum and in a floating regime otherwise. For each regime, we report the mean of log excess returns (EXRET, \% per annum), carry components (CARRY, \% per annum), and exchange rate returns (SPOT, \% per annum), standard deviation (SD, \% per annum) and skewness (SKEW) of log excess returns, and the Sharpe ratio (SR, annualized), both before and after transaction costs. Standard errors, obtained by bootstrapping under the assumption of IID returns, are shown in parentheses. The sample runs from Dec. 1919 to Dec. 2017.

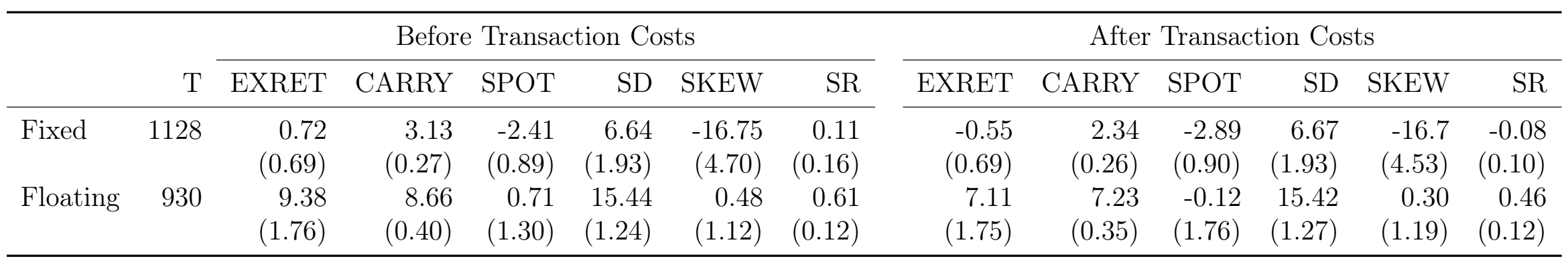




\section{TABLE 4}

\section{Indirect Effect of the Fixed Regime on Floating Carry Returns}

Table 4 reports how the performance of the floating carry trade varies with the extent to which either currency in each floating pair is fixed to some other currency. We categorize floating currency pairs into three subgroups: (i) a Low Mix Floating pair indicates that neither currency in the floating pair is fixed to any other currencies; (ii) a Medium Mix Floating pair indicates that either currency in the floating pair is fixed to less than half of the remaining currencies; and (iii) a High Mix Floating pair indicates that either currency in the floating pair is fixed to more than half of the remaining currencies. For floating carry strategy based on each group, we report the mean of log excess returns (EXRET, \% per annum), carry components (CARRY, \% per annum), and exchange rate returns (SPOT, \% per annum), standard deviation (SD, \% per annum) and skewness (SKEW) of log excess returns, and the Sharpe ratio (SR, annualized), both before and after transaction costs. Standard errors, obtained by bootstrapping under the assumption of IID returns, are shown in parentheses. The sample runs from Dec. 1919 to Dec. 2017.

\begin{tabular}{|c|c|c|c|c|c|c|c|c|c|c|c|c|c|}
\hline & \multirow[b]{2}{*}{$\mathrm{T}$} & \multicolumn{6}{|c|}{ Before Transaction Costs } & \multicolumn{6}{|c|}{ After Transaction Costs } \\
\hline & & EXRET & CARRY & SPOT & $\mathrm{SD}$ & SKEW & $\mathrm{SR}$ & EXRET & CARRY & SPOT & $\mathrm{SD}$ & SKEW & SR \\
\hline $\begin{array}{l}\text { High Mix } \\
\text { Floating }\end{array}$ & 307 & $\begin{array}{r}6.92 \\
(3.53)\end{array}$ & $\begin{array}{r}9.20 \\
(1.06)\end{array}$ & $\begin{array}{r}-2.28 \\
(3.46)\end{array}$ & $\begin{array}{l}17.57 \\
(2.23)\end{array}$ & $\begin{array}{r}-1.32 \\
(1.32)\end{array}$ & $\begin{array}{r}0.39 \\
(0.22)\end{array}$ & $\begin{array}{r}3.52 \\
(3.52)\end{array}$ & $\begin{array}{r}7.21 \\
(0.95)\end{array}$ & $\begin{array}{l}-3.68 \\
(3.56)\end{array}$ & $\begin{array}{l}17.52 \\
(2.34)\end{array}$ & $\begin{array}{r}-1.69 \\
(1.41)\end{array}$ & $\begin{array}{r}0.20 \\
(0.21)\end{array}$ \\
\hline $\begin{array}{l}\text { Medium Mix } \\
\text { Floating }\end{array}$ & 626 & $\begin{array}{r}7.12 \\
(1.68) \\
\end{array}$ & $\begin{array}{r}7.13 \\
(0.41) \\
\end{array}$ & $\begin{array}{r}-0.01 \\
(1.19) \\
\end{array}$ & $\begin{array}{r}12.11 \\
(1.04) \\
\end{array}$ & $\begin{array}{r}1.31 \\
(0.94) \\
\end{array}$ & $\begin{array}{r}0.59 \\
(0.13) \\
\end{array}$ & $\begin{array}{r}4.58 \\
(1.69) \\
\end{array}$ & $\begin{array}{r}6.07 \\
(0.38) \\
\end{array}$ & $\begin{array}{r}-1.49 \\
(1.69) \\
\end{array}$ & $\begin{array}{l}12.22 \\
(1.04)\end{array}$ & $\begin{array}{r}1.11 \\
(0.95)\end{array}$ & $\begin{array}{r}0.37 \\
(0.14)\end{array}$ \\
\hline $\begin{array}{l}\text { Low Mix } \\
\text { Floating }\end{array}$ & 740 & $\begin{array}{l}10.65 \\
(2.06)\end{array}$ & $\begin{array}{r}9.24 \\
(0.39)\end{array}$ & $\begin{array}{r}1.41 \\
(1.38)\end{array}$ & $\begin{array}{r}16.20 \\
(1.56)\end{array}$ & $\begin{array}{r}1.93 \\
(1.24)\end{array}$ & $\begin{array}{r}0.66 \\
(0.12)\end{array}$ & $\begin{array}{r}8.15 \\
(2.05)\end{array}$ & $\begin{array}{r}7.84 \\
(0.33)\end{array}$ & $\begin{array}{r}0.31 \\
(2.02)\end{array}$ & $\begin{array}{r}16.13 \\
(1.56)\end{array}$ & $\begin{array}{r}1.91 \\
(1.25)\end{array}$ & $\begin{array}{r}0.51 \\
(0.12)\end{array}$ \\
\hline
\end{tabular}


TABLE 5

\section{Fixed and Floating Carry Returns over Subperiods}

Table 5 reports descriptive statistics for the performance of the fixed and floating carry trades for each of the three sub-periods, i.e., the interwar period (Panel A), WWII and the Bretton Woods period (Panel B), and the post Bretton Woods period (Panel C). A currency pair is classified as in the fixed regime if its ex ante volatility is below $4 \%$ per annum and in the floating regime otherwise. For each regime, we report the mean of log excess returns (EXRET, \% per annum), carry components (CARRY, \% per annum), and exchange rate returns (SPOT, \% per annum), standard deviation (SD, \% per annum) and skewness (SKEW) of log excess returns, and the Sharpe ratio (SR, annualized), both before and after transaction costs. Standard errors, obtained by bootstrapping under the assumption of IID returns, are shown in parentheses. The sample runs from Dec. 1919 to Dec. 2017.

\begin{tabular}{|c|c|c|c|c|c|c|c|c|c|c|c|c|c|}
\hline & & \multicolumn{6}{|c|}{ Before Transaction Costs } & \multicolumn{6}{|c|}{ After Transaction Costs } \\
\hline & $\mathrm{T}$ & EXRET & CARRY & SPOT & $\mathrm{SD}$ & SKEW & $\mathrm{SR}$ & EXRET & CARRY & SPOT & SD & SKEW & SR \\
\hline \multicolumn{14}{|c|}{ Panel A. Interwar Period (Dec. 1919 to July 1939) } \\
\hline \multirow[t]{2}{*}{ Fixed } & 214 & -1.29 & 5.74 & -7.03 & 13.41 & -10.03 & -0.10 & -2.62 & 4.98 & -7.60 & 13.44 & -10.00 & -0.20 \\
\hline & & $(3.14)$ & $(1.27)$ & $(4.26)$ & $(5.13)$ & $(2.89)$ & $(0.32)$ & $(3.15)$ & $(1.25)$ & $(4.26)$ & $(5.12)$ & $(2.79)$ & $(0.25)$ \\
\hline \multirow[t]{2}{*}{ Floating } & 223 & 19.79 & 10.55 & 9.24 & 27.52 & 0.07 & 0.72 & 17.10 & 9.03 & 8.07 & 27.56 & -0.02 & 0.62 \\
\hline & & $(6.33)$ & $(0.97)$ & $(6.46)$ & $(2.73)$ & $(0.76)$ & $(0.24)$ & $(6.34)$ & $(0.90)$ & $(6.45)$ & $(2.80)$ & $(0.80)$ & $(0.24)$ \\
\hline
\end{tabular}

Panel B. WWII and Bretton Woods Era (Aug. 1939 to July 1971)

\begin{tabular}{lrrrrrrrrrrrrr}
\hline Fixed & 384 & 1.27 & 2.70 & -1.43 & 4.00 & -10.79 & 0.32 & -0.19 & 1.55 & -1.75 & 4.02 & -11.08 & -0.05 \\
& & $(0.70)$ & $(0.17)$ & $(0.75)$ & $(1.25)$ & $(3.41)$ & $(0.46)$ & $(0.70)$ & $(0.13)$ & $(0.75)$ & $(1.28)$ & $(3.34)$ & $(0.25)$ \\
Floating & \multirow{2}{*}{151} & 5.54 & 7.42 & -1.88 & 9.24 & 1.81 & 0.60 & 1.90 & 5.04 & -3.14 & 8.88 & 0.82 & 0.21 \\
& & $(2.60)$ & $(1.71)$ & $(1.79)$ & $(1.91)$ & $(2.23)$ & $(0.28)$ & $(2.49)$ & $(1.49)$ & $(1.84)$ & $(1.82)$ & $(2.38)$ & $(0.28)$ \\
\hline
\end{tabular}

Panel C. Post Bretton Woods Era (Aug. 1971 to Dec. 2017)

\begin{tabular}{lrrrrrrrrrrrrr}
\hline Fixed & 530 & 1.13 & 2.39 & -1.26 & 3.13 & -3.89 & 0.36 & 0.03 & 1.85 & -1.82 & 3.19 & -4.84 & 0.01 \\
& & $(0.47)$ & $(0.18)$ & $(0.53)$ & $(0.47)$ & $(1.82)$ & $(0.19)$ & $(0.48)$ & $(0.15)$ & $(0.50)$ & $(0.51)$ & $(1.79)$ & $(0.16)$ \\
Floating & 556 & 6.24 & 8.24 & -2.00 & 8.25 & -0.86 & 0.76 & 4.51 & 7.10 & -2.58 & 8.28 & -0.88 & 0.55 \\
& & $(1.20)$ & $(0.26)$ & $(1.25)$ & $(0.37)$ & $(0.20)$ & $(0.16)$ & $(1.21)$ & $(0.22)$ & $(1.22)$ & $(0.38)$ & $(0.22)$ & $(0.16)$ \\
\hline
\end{tabular}


TABLE 6

\section{Floating and Fixed Carry Returns and Exchange Rate Regime Shifts}

Table 6 reports the relationship between exchange rate regime shifts and carry trade returns. Using GBP as the reference currency, we regress the monthly spot returns (basis points) for the floating and fixed carry trades on dummy variables indicating fixed-to-floating $\left(D_{\text {Fixed } \rightarrow \text { Float }}\right)$ and floating-to-fixed $\left(D_{\text {Float } \rightarrow \text { Fixed }}\right)$ regime changes in the investment universe, controlling for volatility risks of the U.S. equity market $(\triangle \mathrm{EQV})$ and of floating currency pairs in the foreign exchange market $(\Delta \mathrm{FXV})$. We then repeat this regression for monthly returns of each of the long (Long) and short (Short) legs of the floating and fixed carry trades. Volatility is measured as the exponentially weighted moving average of daily returns and volatility risk is measured as the one-month first difference of volatility. $*, * *$, and *** indicate statistical significance at the $10 \%, 5 \%$, and $1 \%$ levels, respectively. The sample runs from Dec. 1919 to Dec. 2017. 
TABLE 6

Floating and Fixed Carry Returns and Exchange Rate Regime Shifts (cont.)

\begin{tabular}{|c|c|c|c|c|c|c|}
\hline & & CONSTANT & $D_{\text {Fixed } \rightarrow \text { Float }}$ & $D_{\text {Float } \rightarrow \text { Fixed }}$ & $\Delta \mathrm{FXV}$ & $\Delta \mathrm{EQV}$ \\
\hline \multirow[t]{3}{*}{ (1) } & Floating Carry & 32 & $-116 * * *$ & 0 & & \\
\hline & Long & 0 & -15 & -22 & & \\
\hline & Short & $-32 *$ & $102 * * *$ & -23 & & \\
\hline \multirow[t]{3}{*}{$(2)$} & Fixed Carry & -3 & $-48 * *$ & -11 & & \\
\hline & Long & 10 & -16 & -31 & & \\
\hline & Short & $12 *$ & $32 * * *$ & $-20 *$ & & \\
\hline \multirow[t]{3}{*}{ (3) } & Floating Carry & 3 & & & $-9 *$ & \\
\hline & Long & -11 & & & 0 & \\
\hline & Short & -14 & & & $10 * *$ & \\
\hline \multirow[t]{3}{*}{ (4) } & Fixed Carry & $-19 * *$ & & & -2 & \\
\hline & Long & -6 & & & 0 & \\
\hline & Short & $-13 * *$ & & & 2 & \\
\hline \multirow[t]{3}{*}{$(5)$} & Floating Carry & 6 & & & & $-3 *$ \\
\hline & Long & -11 & & & & -2 \\
\hline & Short & -17 & & & & 2 \\
\hline \multirow[t]{3}{*}{$(6)$} & Fixed Carry & $-18 * *$ & & & & 0 \\
\hline & Long & -6 & & & & 1 \\
\hline & Short & $13 * *$ & & & & 0 \\
\hline \multirow[t]{3}{*}{ (7) } & Floating Carry & 28 & $-112 * * *$ & 1 & -8 & \\
\hline & Long & 0 & -15 & -23 & 1 & \\
\hline & Short & -28 & $97 * * *$ & -23 & $9 *$ & \\
\hline \multirow[t]{3}{*}{ (8) } & Fixed Carry & -3 & $-48 * *$ & -11 & 0 & \\
\hline & Long & 10 & -16 & -31 & 0 & \\
\hline & Short & $13 *$ & $32 * * *$ & $-20 *$ & 1 & \\
\hline \multirow[t]{3}{*}{ (9) } & Floating Carry & $33 *$ & $-114 * * *$ & -3 & & $-3 *$ \\
\hline & Long & 0 & -14 & -24 & & -2 \\
\hline & Short & $-32 *$ & $100 * * *$ & -21 & & 2 \\
\hline \multirow[t]{3}{*}{ (10) } & Fixed Carry & -3 & $-49 * *$ & -11 & & 0 \\
\hline & Long & 9 & -17 & -30 & & 1 \\
\hline & Short & $12 *$ & $32 * * *$ & $-19 *$ & & 0 \\
\hline
\end{tabular}




\title{
Internet Appendix to "Currency Regimes and the Carry Trade"
}

\author{
- NOT FOR PUBLICATION -
}

\section{A. Robustness Tests for Floating and Fixed Carry Returns}

\section{A1. Distinguishing Regime from Volatility}

Given that we classify exchange rate regimes based on cross rate volatility, it could be that carry trade returns are dependent on volatility per se rather than on regimes classified by a given volatility threshold. To clearly distinguish between these two types of dependence, we condition the carry trade strategy on a range of volatility thresholds. We sort currency pairs into six groups based on a range of volatilities: $2 \%, 4 \%, 8 \%, 10 \%$ and $12 \%$. A linear carry trade strategy is constructed within each volatility group. Note that the first two groups, i.e., currency pairs with volatilities below $2 \%$ and between $2 \%$ and $4 \%$, correspond to the fixed regime and the remaining four groups correspond to the floating regime, as defined in the previous section.

Although the expected return to the carry trade increases with the volatility of underlying exchange rates, the risk-adjusted return measured by the Sharpe ratio does not exhibit the same monotonicity. Once a currency pair enters into the floating regime, i.e., above the $4 \%$ threshold, the Sharpe ratio does not increase with volatility both before and after transaction costs (Table IA.1). Therefore, our evidence rejects the hypothesis that risk-adjusted carry returns are dependent on volatility per se.

\section{A2. Varying Volatility Threshold}

Our volatility-based regime classification is based upon two inputs: the volatility measure and the threshold. We verify that our results are robust to a range of volatility thresholds up to $10 \%$. Figure IA.1 graphs the Sharpe ratio of the fixed and floating carry trades, respectively, both before and after transaction costs, and also displays the 5th and the 95th percentiles. A threshold of a little higher than $6 \%$ is required to produce a significantly positive Sharpe ratio for the fixed carry trade before transaction costs, and one of $10 \%$ after transaction costs. However, classifying a currency pair as fixed when its volatility is $6 \%$, let alone $10 \%$, would be inconsistent with the observed de jure regime classification during our sample period. In contrast, varying the volatility threshold does not have a significant effect on the Sharpe ratio of the floating carry trade.

\section{A3. Alternative Volatility-Based Regime Classifications}

We now verify the robustness of our results using alternative regime classifications. Table IA.2 summarizes descriptive statistics of returns to the fixed and floating carry trades, respectively, using the methodology in Shambaugh (2004) which measures volatility as the 
absolute difference between the highest and the lowest exchange rate over the past year (Panel A) and in Menkhoff, Sarno, Schmeling, and Schrimpf (2012) which measures volatility as the mean absolute daily return within each month (Panel B). In both cases, we apply the same $4 \%$ volatility threshold and find our results hold. The annualized floating carry returns using the Shambaugh (2004) and Menkhoff, Sarno, Schmeling, and Schrimpf (2012) methods are $5.86 \%$ and $8.86 \%$ respectively, whereas the fixed carry returns are effectively zero.

\section{A4. Alternative Method of Distinguishing the Time Series and Cross Section of Regime-Dependence}

In Section 4.6, we verified that the variation of carry trade returns is present in both the time series and the cross section of exchange rate regimes by examining the performance of the floating and fixed carry strategies in three subsample periods. Here, we briefly discussed

an alternative approach to modelling the time dimension of currency regimes by classifying each month according to whether there are more fixed currency pairs than floating ones or vice versa.

The results are summarized in Table IA.3. Before and after transaction costs, both the excess return (9.99\% and $6.57 \%$ ) and the Sharpe ratio (0.53 and 0.35 ) of the floating carry trade remain positive even in those months where the fraction of fixed currency pairs is more than half of all currency pairs in the sample.

\section{A5. Extended Sample}

Table IA.4 presents the detailed results for the regime-dependence of carry returns in an extended sample with emerging market currencies.

\section{A6. Base Carry Trade}

In section 4.5, we discussed results whether our finding of regime-dependence holds for different base currencies. The detailed results are summarized in Table IA.5. We find that only the floating base carry trade delivers outsized returns while the fixed base carry trade is not profitable, regardless of whether the base currency is the U.S. dollar (Panel A), the GBP (Panel B) or the Deutsche mark (or Euro from 1999 onwards) (Panel C).

\section{A7. Exclusion of the Period of 1939 to 1958}

Restrictions on foreign exchange trading in London existed between the outbreak of war in Sept. 1939 and the reintroduction of sterling convertibility for non-residents in Dec. 1958. Our main results regarding the regime-dependence of carry returns (Table IA.6) are robust to the exclusion of this period from our sample. 


\section{B. Robustness Tests for the Relationship between Floating and Fixed Carry Returns and Regime Shifts}

\section{B1. U.S. dollar as the Reference Currency}

In Section 5, we examine the relationship between floating and fixed carry strategies and regime shifts by decomposing the return of each strategy into contributions from its long and short legs using the pound sterling (GBP) as the reference currency. Here, we verify the robustness of our results using the US dollar (USD) as the reference currency. Results are detailed in Table IA.7.

\section{B2. The Fraction of Regime-Switching Currency Pairs}

In Section 5, we examine the relationship between floating and fixed carry strategies and regime shifts represented by dummy variables. Here, we verify the robustness of our results using the fraction of currency pairs in the fixed (floating) regime switching to floating (fixed) in each month. Results are detailed in Table IA.8.

\section{B3. Spot Returns after Transaction Costs}

In Section 5, we examine the relationship between the realized spot returns before transaction costs of the floating and fixed carry strategies and regime shifts. Here, we verify our main results in Section 5 using realized spot returns after transaction costs. The results are summarized in Table IA.9.

\section{B4. Alternative Regime Shift Indicators}

To further validate our results, we modify the regime shift indicator to exclude regime shifts triggered by only very small volatility changes that pass the threshold (e.g., volatility changes from $3.9 \%$ to $4.1 \%$ ). Table IA.10 summarizes the results for regressions using these modified regime change indicators. Volatility has to increase by at least $1 \%$ to qualify for a fixed-tofloating switch in Panel A and by at least $2 \%$ in Panel B. In both cases, the fixed-to-floating regime shock negatively impacts carry trade returns.

Since our sample of fixed-to-floating regime switches includes an extreme carry trade return of $-44.9 \%$ in June to July 1931, we check our regression results excluding this outlier (Panel C). Again, carry trade returns remain negatively correlated with fixed-to-floating switches. Finally, to disentangle the confounding effects of fixed-to-floating and floating-tofixed regime shifts, we exclude those months in which both regime shifts occur (Panel D). We find that fixed-to-floating regime shifts still have a statistically significant adverse impact on floating carry returns. Furthermore, the average decline in returns becomes greater $(-175$ basis points, after transaction costs). 


\section{B5. Exclusion of the Period of 1939 to 1958}

For the same reason explained in Section A7, we verify that our main results regarding the relationship between floating and fixed carry returns and regime shifts (Table IA.11) are robust to the exclusion of the period of 1939 to 1958 from our sample.

\section{B6. Historical Events Associated with Floating Carry Strategy Losses at the Time of Currency Peg Collapses}

Table IA.12 exemplifies noteworthy flight-to-safety episodes in the history of international finance that are associated with dramatic losses to the floating carry strategy at the time of currency peg collapses. These events are documented by secondary sources such as Eichengreen (1996), Aldcroft and Oliver (1998), James (2012), and Reinhart and Rogoff (2011).

\section{REFERENCES}

Aldcroft, D. H.; and M. J. Oliver. Exchange Rate Regimes in the Twentieth Century. Cheltenham, UK: Edward Elgar (1998).

Eichengreen, B. Globalizing Capital: A History of the International Monetary System. Princeton, NJ: Princeton University Press (1996).

James, H. Making the European Monetary Union. Cambridge, MA: Harvard University Press (2012).

Menkhoff, L.; L. Sarno; M. Schmeling; and A. Schrimpf. "Carry Trades and Global Foreign Exchange Volatility." Journal of Finance, 67 (2012), 681-718.

Reinhart, C. M.; and K. S. Rogoff. "From Financial Crash to Debt Crisis." American Economic Review, 101 (2011), 1676-1706.

Shambaugh, J. "The Effects of Fixed Exchange Rates on Monetary Policy." Quarterly Journal of Economcis, 119 (2004), 301-352. 
Table IA.1

\section{Carry Trade Performance Conditional on Exchange Rate Volatility}

Table IA.1 reports how the performance of the carry trade varies with ex ante exchange rate volatility. All currency pairs are sorted into 6 categories by the cross rate volatility measured at the beginning of each month. The first two categories, i.e., volatility lower than $2 \%([0,2])$ and volatility between $2 \%$ and $4 \%([2,4])$, comprise currency pairs in the fixed regime. The remaining categories comprise floating currency pairs. For each volatility category, we report the mean of log excess returns (EXRET, \% per annum), carry components (CARRY, \% per annum), and exchange rate returns (SPOT, \% per annum), standard deviation (SD, \% per annum) and skewness (SKEW) of log excess returns, and the Sharpe ratio (SR, annualized). Standard errors, obtained by bootstrapping under the assumption of independent and identically distributed (IID) returns, are shown in parentheses. The sample runs from Dec. 1919 to Dec. 2017.

\begin{tabular}{|c|c|c|c|c|c|c|c|c|c|c|c|c|c|}
\hline \multirow[b]{2}{*}{ Volatility } & \multirow[b]{2}{*}{$\mathrm{T}$} & \multicolumn{6}{|c|}{ Before Transaction Costs } & \multicolumn{6}{|c|}{ After Transaction Costs } \\
\hline & & EXRET & CARRY & SPOT & $\mathrm{SD}$ & SKEW & SR & EXRET & CARRY & SPOT & SD & SKEW & SR \\
\hline \multirow[t]{2}{*}[0,2]{} & 928 & 0.07 & 2.13 & -2.06 & 6.98 & -21.70 & 0.01 & -0.82 & 1.53 & -2.35 & 6.99 & -21.72 & -0.12 \\
\hline & & $(0.80)$ & $(0.31)$ & $(1.12)$ & $(2.78)$ & $(6.12)$ & $(0.19)$ & $(0.80)$ & $(0.30)$ & $(1.06)$ & $(2.79)$ & $(5.86)$ & $(0.10)$ \\
\hline \multirow[t]{2}{*}[2,4]{} & 750 & 1.87 & 4.71 & -2.84 & 8.12 & -10.65 & 0.23 & -0.47 & 3.47 & -3.94 & 8.16 & -10.90 & -0.06 \\
\hline & & $(1.03)$ & $(0.39)$ & $(1.14)$ & $(1.96)$ & $(3.38)$ & $(0.20)$ & $(1.04)$ & $(0.36)$ & $(1.27)$ & $(1.98)$ & $(3.16)$ & $(0.13)$ \\
\hline \multirow[t]{2}{*}[4,6]{} & 816 & 5.29 & 6.67 & -1.38 & 8.33 & 0.19 & 0.63 & 2.99 & 5.42 & -2.42 & 8.28 & -0.20 & 0.36 \\
\hline & & (1.02) & $(0.39)$ & $(0.96)$ & $(0.78)$ & (1.41) & $(0.13)$ & $(1.01)$ & $(0.34)$ & $(0.95)$ & $(0.77)$ & $(1.36)$ & $(0.13)$ \\
\hline \multirow[t]{2}{*}[6,8]{} & 672 & 6.57 & 7.84 & -1.27 & 10.74 & -1.78 & 0.61 & 3.44 & 6.48 & -3.04 & 10.60 & -2.04 & 0.32 \\
\hline & & $(1.43)$ & $(0.48)$ & $(0.73)$ & (1.06) & (1.39) & $(0.16)$ & $(1.42)$ & $(0.41)$ & $(1.40)$ & (1.07) & $(1.40)$ & $(0.15)$ \\
\hline \multirow[t]{2}{*}[8,12]{} & 632 & 8.11 & 8.44 & -0.33 & 16.52 & -2.01 & 0.49 & 4.43 & 7.00 & -2.57 & 16.49 & -2.16 & 0.27 \\
\hline & & $(2.29)$ & $(0.45)$ & $(2.04)$ & (1.63) & (1.18) & $(0.17)$ & $(2.29)$ & $(0.37)$ & $(2.28)$ & $(1.65)$ & (1.18) & $(0.15)$ \\
\hline \multirow[t]{2}{*}{$>12$} & 695 & 13.66 & 11.91 & 1.74 & 25.55 & 0.20 & 0.53 & 10.03 & 10.21 & -0.18 & 25.52 & 0.10 & 0.39 \\
\hline & & $(3.33)$ & $(0.61)$ & $(2.10)$ & (1.79) & $(0.73)$ & $(0.13)$ & (3.33) & $(0.55)$ & $(3.38)$ & $(1.80)$ & $(0.75)$ & $(0.13)$ \\
\hline
\end{tabular}


Table IA.2

Fixed and Floating Carry Returns Based on Alternative Classifications of Exchange Rate Regimes

Table IA.2 reports descriptive statistics for the performance of the fixed and floating carry trade strategies based on alternative classifications, i.e., Shambaugh (2004) which measures volatility as the absolute difference between the highest and lowest exchange rate over the past year (Panel A) and Menkhoff, Sarno, Schmeling, and Schrimpf (2012) which measures volatility as the mean absolute daily return within each month (Panel B). A currency pair is classified as in the fixed regime if its ex ante volatility is below $4 \%$ per annum and in the floating regime otherwise. For each regime, we report the mean of log excess returns (EXRET, \% per annum), carry components (CARRY, \% per annum), and exchange rate returns (SPOT, \% per annum), standard deviation (SD, \% per annum) and skewness (SKEW) of log excess returns, and the Sharpe ratio (SR, annualized). Standard errors, obtained by bootstrapping under the assumption of independent and identically distributed (IID) returns, are shown in parentheses. The sample runs from Dec. 1919 to Dec. 2017.

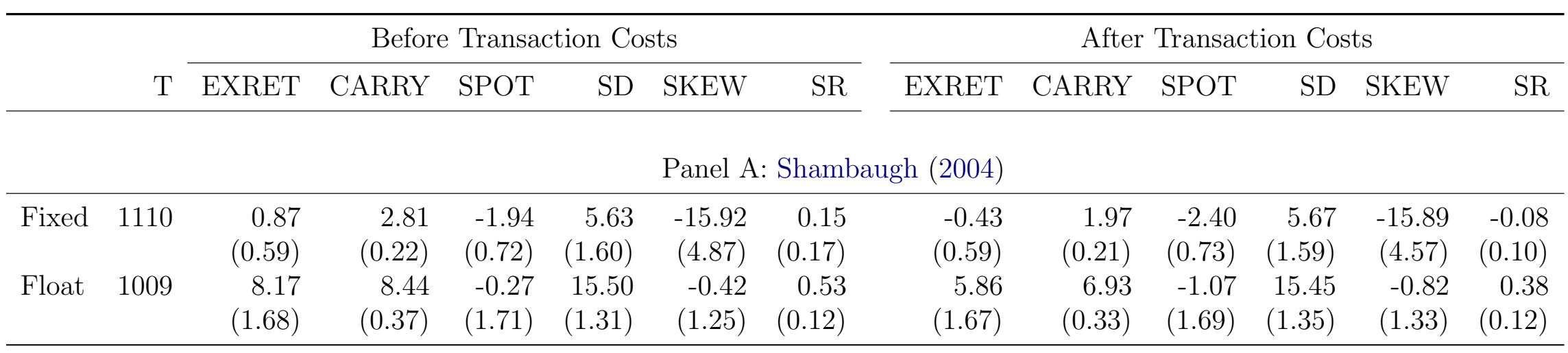

Panel B: Menkhoff, Sarno, Schmeling, and Schrimpf (2012)

\begin{tabular}{rrrrrrrrrrrrrrr}
\hline Fixed & 1162 & 1.37 & 4.46 & -3.09 & 6.32 & -11.23 & 0.22 & -0.50 & 3.46 & -3.96 & 6.34 & -11.19 & -0.08 \\
& & $(0.65)$ & $(0.23)$ & $(0.67)$ & $(1.35)$ & $(3.83)$ & $(0.15)$ & $(0.65)$ & $(0.22)$ & $(0.79)$ & $(1.34)$ & $(3.73)$ & $(0.10)$ \\
Float & \multirow{2}{*}{742} & 11.58 & 9.54 & 2.04 & 17.95 & 0.87 & 0.64 & 8.86 & 8.14 & 0.72 & 17.85 & 0.66 & 0.50 \\
& & $(2.28)$ & $(0.43)$ & $(1.43)$ & $(1.50)$ & $(1.04)$ & $(0.13)$ & $(2.27)$ & $(0.39)$ & $(2.29)$ & $(1.52)$ & $(1.11)$ & $(0.13)$ \\
\hline
\end{tabular}


Table IA.3

\section{Variation of Fixed and Floating Carry Returns with the Fraction of Fixed Currency Pairs}

Table IA.3 reports descriptive statistics for the performance of the fixed and floating carry trade strategies for each of the two subsamples defined by whether the fraction of fixed currency pairs in a month is above 0.5 (Panel A) or below 0.5 (Panel B). A currency pair is classified as in the fixed regime if its ex ante volatility is below $4 \%$ per annum and in the floating regime otherwise. For each regime, we report the mean of log excess returns (EXRET, \% per annum), carry components (CARRY, \% per annum), and exchange rate returns (SPOT, \% per annum), standard deviation (SD, \% per annum) and skewness (SKEW) of log excess returns, and the Sharpe ratio (SR, annualized). Standard errors, obtained by bootstrapping under the assumption of independent and identically distributed (IID) returns, are shown in parentheses. The sample runs from Dec. 1919 to Dec. 2017.

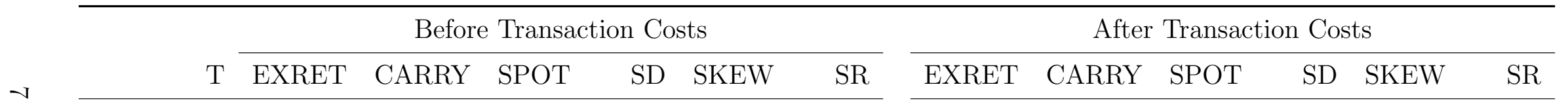

Panel A. Fraction of Fixed Currency Pairs $>0.5$

\begin{tabular}{lrrrrrrrrrrrrrr}
\hline Fixed & 474 & 0.55 & 3.46 & -2.91 & 5.52 & -8.92 & 0.10 & -0.82 & 2.38 & -3.20 & 5.57 & -8.97 & -0.15 \\
& & $(0.87)$ & $(0.31)$ & $(1.06)$ & $(1.28)$ & $(1.65)$ & $(0.22)$ & $(0.88)$ & $(0.29)$ & $(1.06)$ & $(1.29)$ & $(1.62)$ & $(0.15)$ \\
Float & 228 & 9.99 & 9.67 & 0.32 & 18.97 & -1.33 & 0.53 & 6.57 & 7.50 & -0.93 & 18.89 & -1.67 & 0.35 \\
& & $(4.42)$ & $(1.38)$ & $(4.47)$ & $(2.74)$ & $(1.46)$ & $(0.27)$ & $(4.40)$ & $(1.25)$ & $(4.46)$ & $(2.88)$ & $(1.54)$ & $(0.26)$ \\
\hline
\end{tabular}

Panel B. Fraction of Fixed Currency Pairs $<0.5$

\begin{tabular}{lrrrrrrrrrrrrr}
\hline Fixed & 654 & 0.84 & 2.90 & -2.05 & 7.35 & -18.59 & 0.11 & -0.36 & 2.31 & -2.67 & 7.36 & -18.60 & -0.05 \\
& & $(0.99)$ & $(0.39)$ & $(1.25)$ & $(3.00)$ & $(7.22)$ & $(0.27)$ & $(0.99)$ & $(0.38)$ & $(1.32)$ & $(3.00)$ & $(6.85)$ & $(0.17)$ \\
Float & 702 & 9.18 & 8.34 & 0.84 & 14.12 & 1.86 & 0.65 & 7.28 & 7.14 & 0.14 & 14.13 & 1.82 & 0.52 \\
& & $(1.87)$ & $(0.27)$ & $(1.24)$ & $(1.31)$ & $(1.13)$ & $(0.12)$ & $(1.87)$ & $(0.23)$ & $(1.86)$ & $(1.31)$ & $(1.13)$ & $(0.12)$ \\
\hline
\end{tabular}


Table IA.4

Fixed and Floating Carry Returns When Emerging Market Currencies Are Included

Table IA.4 reports descriptive statistics for the performance of the fixed and floating carry trade strategies when USD-based exchange rates of emerging market currencies are included (Panel A for only emerging market currencies and Panel B for currencies of both developed and emerging markets). For each panel, we report the mean of log excess returns (EXRET, \% per annum), carry components (CARRY, \% per annum), and exchange rate returns (SPOT, \% per annum), standard deviation (SD, $\%$ per annum) and skewness (SKEW) of log excess returns, and the Sharpe ratio (SR, annualized). Standard errors, obtained by bootstrapping under the assumption of independent and identically distributed (IID) returns, are shown in parentheses. The sample runs from Oct. 1983 to Dec. 2013.

\begin{tabular}{|c|c|c|c|c|c|c|c|c|c|c|c|c|c|}
\hline \multirow{2}{*}{\multicolumn{2}{|c|}{$\mathrm{T}$}} & \multicolumn{6}{|c|}{ Before Transaction Costs } & \multicolumn{6}{|c|}{ After Transaction Costs } \\
\hline & & EXRET & CARRY & SPOT & $\mathrm{SD}$ & SKEW & $\mathrm{SR}$ & EXRET & CARRY & SPOT & $\mathrm{SD}$ & SKEW & $\mathrm{SR}$ \\
\hline \multicolumn{14}{|c|}{ Panel A. Emerging Markets Only } \\
\hline \multirow[t]{2}{*}{ Fixed } & 359 & 0.49 & 1.99 & -1.51 & 2.36 & -2.57 & 0.21 & 0.00 & 1.75 & -1.75 & 2.38 & -2.78 & 0.00 \\
\hline & & $(0.43)$ & $(0.14)$ & $(0.24)$ & $(0.29)$ & (1.07) & $(0.20)$ & $(0.43)$ & $(0.13)$ & $(0.44)$ & $(0.30)$ & (1.07) & $(0.19)$ \\
\hline \multirow{2}{*}{ Float } & 363 & 12.74 & 16.91 & -4.16 & 15.66 & 1.46 & 0.81 & 10.37 & 15.13 & -4.76 & 15.28 & 1.31 & 0.68 \\
\hline & & $(2.85)$ & $(1.40)$ & $(2.31)$ & $(1.19)$ & $(0.36)$ & $(0.16)$ & $(2.78)$ & $(1.28)$ & $(2.27)$ & $(1.16)$ & $(0.39)$ & $(0.17)$ \\
\hline \multicolumn{14}{|c|}{ Panel B: Both Developed and Emerging Markets } \\
\hline \multirow[t]{2}{*}{ Fixed } & 363 & 1.13 & 2.51 & -1.38 & 2.13 & -1.86 & 0.53 & 0.47 & 2.21 & -1.74 & 2.16 & -2.05 & 0.22 \\
\hline & & $(0.38)$ & $(0.13)$ & $(0.18)$ & $(0.22)$ & $(0.89)$ & $(0.21)$ & $(0.39)$ & $(0.12)$ & $(0.39)$ & $(0.23)$ & $(0.86)$ & $(0.19)$ \\
\hline \multirow[t]{2}{*}{ Float } & 363 & 13.89 & 16.17 & -2.28 & 12.99 & 1.66 & 1.07 & 11.49 & 14.43 & -2.94 & 12.68 & 1.52 & 0.91 \\
\hline & & $(2.36)$ & $(1.24)$ & $(1.39)$ & $(0.99)$ & $(0.30)$ & $(0.15)$ & $(2.30)$ & (1.14) & $(1.85)$ & $(0.97)$ & $(0.33)$ & $(0.16)$ \\
\hline
\end{tabular}


Table IA.5

\section{Regime-Dependent Returns to the Base Carry Trade Strategies}

Table IA.5 reports descriptive statistics for the performance of the fixed and floating base carry trade strategies for three base currencies, USD (Panel A), GBP (Panel B), and DEM (EUR) (Panel C). A currency pair is classified as in the fixed regime if its ex ante volatility is below $4 \%$ per annum and in the floating regime otherwise. For each regime, we report the mean of log excess returns (EXRET, \% per annum), carry components (CARRY, \% per annum), and exchange rate returns (SPOT, \% per annum), standard deviation (SD, \% per annum) and skewness (SKEW) of log excess returns, and the Sharpe ratio (SR, annualized). Standard errors, obtained by bootstrapping under the assumption of independent and identically distributed (IID) returns, are shown in parentheses. The sample runs from Dec. 1919 to Dec. 2017.

\begin{tabular}{|c|c|c|c|c|c|c|c|c|c|c|c|c|}
\hline \multirow[b]{2}{*}{$\mathrm{T}$} & \multicolumn{6}{|c|}{ Before Transaction Costs } & \multicolumn{6}{|c|}{ After Transaction Costs } \\
\hline & EXRET & CARRY & SPOT & SD & SKEW & SR & EXRET & CARRY & SPOT & SD & SKEW & SR \\
\hline
\end{tabular}

Panel A. Average Forward Discount against USD

\begin{tabular}{rrrrrrrrrrrrrrr}
\hline & Fixed & 704 & 0.75 & 1.22 & -0.47 & 3.58 & -4.86 & 0.21 & -0.42 & 0.40 & -0.82 & 3.66 & -4.90 & -0.11 \\
& & $(0.46)$ & $(0.10)$ & $(0.48)$ & $(0.50)$ & $(1.47)$ & $(0.15)$ & $(0.47)$ & $(0.09)$ & $(0.49)$ & $(0.50)$ & $(1.40)$ & $(0.12)$ \\
& & & & & &
\end{tabular}

Panel B. Average Forward Discount against GBP

\begin{tabular}{rrrrrrrrrrrrrr}
\hline Fixed & 597 & -0.49 & 1.14 & -1.62 & 5.03 & -5.61 & -0.10 & -1.19 & 0.62 & -1.81 & 5.11 & -6.03 & -0.23 \\
& & $(0.72)$ & $(0.11)$ & $(0.76)$ & $(0.92)$ & $(2.71)$ & $(0.14)$ & $(0.73)$ & $(0.11)$ & $(0.77)$ & $(0.97)$ & $(2.74)$ & $(0.12)$ \\
Float & 910 & 3.52 & 2.04 & 1.48 & 10.21 & 0.94 & 0.34 & 2.80 & 1.52 & 1.27 & 10.20 & 0.90 & 0.27 \\
& & $(1.17)$ & $(0.10)$ & $(1.16)$ & $(0.70)$ & $(0.82)$ & $(0.11)$ & $(1.17)$ & $(0.09)$ & $(1.16)$ & $(0.69)$ & $(0.82)$ & $(0.11)$ \\
\hline
\end{tabular}

Panel C. Average Forward Discount against DEM (EUR)

\begin{tabular}{lrrrrrrrrrrrrr}
\hline Fixed & 758 & 0.63 & 1.44 & -0.81 & 2.66 & 1.56 & 0.24 & -0.68 & 0.71 & -1.39 & 2.49 & -1.98 & -0.27 \\
& & $(0.33)$ & $(0.07)$ & $(0.33)$ & $(0.40)$ & $(3.16)$ & $(0.13)$ & $(0.31)$ & $(0.06)$ & $(0.31)$ & $(0.28)$ & $(1.73)$ & $(0.12)$ \\
Float & 738 & 5.82 & 3.10 & 2.72 & 13.50 & 3.77 & 0.43 & 4.57 & 2.19 & 2.38 & 13.52 & 3.71 & 0.34 \\
& & $(1.73)$ & $(0.12)$ & $(1.72)$ & $(1.69)$ & $(1.62)$ & $(0.11)$ & $(1.73)$ & $(0.10)$ & $(1.72)$ & $(1.69)$ & $(1.64)$ & $(0.11)$ \\
\hline
\end{tabular}


Table IA.6

Fixed and Floating Carry Returns When the Period of 1939 to 1958 Is Excluded

Table IA.6 reports descriptive statistics for the performance of the fixed and floating carry trade strategies in periods excluding that of 1939 to 1958. A currency pair is classified as in a fixed regime if its ex ante volatility is below $4 \%$ per annum and in a floating regime otherwise. For each regime, we report the mean of log excess returns (EXRET, \% per annum), carry components (CARRY, \% per annum), and exchange rate returns (SPOT, \% per annum), standard deviation (SD, \% per annum) and skewness (SKEW) of log excess returns, and the Sharpe ratio (SR, annualized). Standard errors, obtained by bootstrapping under the assumption of independent and identically distributed (IID) returns, are shown in parentheses. The sample runs from December 1919 to December, 2017, excluding the period from Aug. 1939 to Dec. 1958.

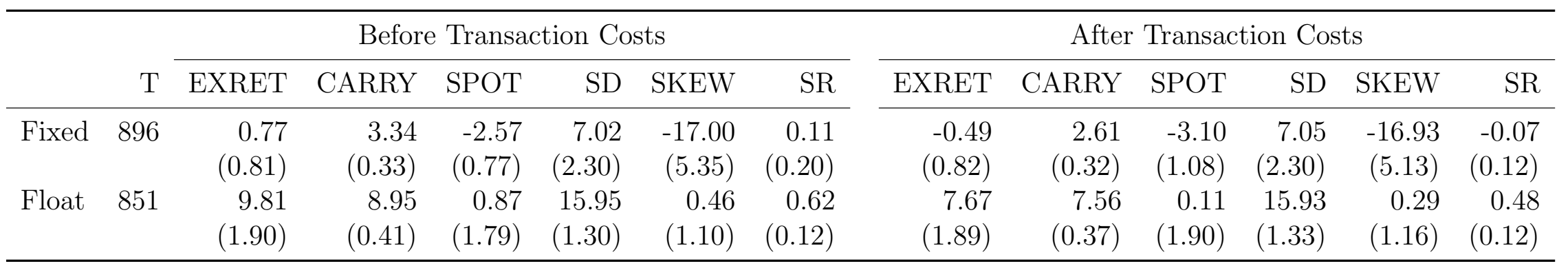


Table IA.7

\section{Floating and Fixed Carry Returns and Exchange Rate Regime Shifts Using USD as the Reference Currency}

Table IA.7 reports the relationship between exchange rate regime shifts and carry trade returns. Using USD as the reference currency, we regress the monthly spot returns (basis points) for the floating and fixed carry trades on dummy variables indicating fixed-to-floating $\left(D_{\text {Fixed } \rightarrow \text { Float }}\right)$ and floating-to-fixed $\left(D_{\text {Float } \rightarrow \text { Fixed }}\right)$ regime changes in the investment universe, controlling for volatility risks of the U.S. equity market $(\triangle \mathrm{EQV})$ and of floating currency pairs in the foreign exchange market $(\Delta \mathrm{FXV})$. We then repeat this regression for monthly returns of each of the long (Long) and short (Short) legs of the floating and fixed carry trades. Volatility is measured as the exponentially weighted moving average of daily returns and volatility risk is measured as the one-month first difference of volatility. $*$, ** , and *** indicates statistical significance at $10 \%, 5 \%$, and $1 \%$ levels, respectively. The sample runs from Dec. 1919 to Dec. 2017. 
Table IA. 7

Floating and Fixed Carry Returns and Exchange Rate Regime Shifts Using USD as the Reference Currency (cont.)

\begin{tabular}{|c|c|c|c|c|c|c|}
\hline & & Constant & $D_{\text {Fixed } \rightarrow \text { Float }}$ & $D_{\text {Float } \rightarrow \text { Fixed }}$ & $\Delta \mathrm{FXV}$ & $\triangle \mathrm{EQV}$ \\
\hline \multirow[t]{3}{*}{ (1) } & Floating Carry & 32 & -116 *** & 0 & & \\
\hline & Long & -19 & -36 & 15 & & \\
\hline & Short & $-51 * * *$ & $80 * * *$ & 15 & & \\
\hline \multirow[t]{3}{*}{$(2)$} & Fixed Carry & -3 & $-48 * *$ & -11 & & \\
\hline & Long & 3 & -12 & -17 & & \\
\hline & Short & 5 & $35 * *$ & -6 & & \\
\hline \multirow[t]{3}{*}{$(3)$} & Floating Carry & 3 & & & $-9 *$ & \\
\hline & Long & $-21 *$ & & & 1 & \\
\hline & Short & $-24 *$ & & & $10 * *$ & \\
\hline \multirow[t]{3}{*}{$(4)$} & Fixed Carry & $-19 * *$ & & & -2 & \\
\hline & Long & -7 & & & -1 & \\
\hline & Short & $11 *$ & & & 1 & \\
\hline \multirow[t]{3}{*}{$(5)$} & Floating Carry & 6 & & & & $-3 *$ \\
\hline & Long & $-22 *$ & & & & $-3 *$ \\
\hline & Short & $-27 * *$ & & & & 0 \\
\hline \multirow[t]{3}{*}{$(6)$} & Fixed Carry & $-18 * *$ & & & & 0 \\
\hline & Long & -7 & & & & 0 \\
\hline & Short & $11 *$ & & & & 0 \\
\hline \multirow[t]{3}{*}{$(7)$} & Floating Carry & 28 & $-112 * * *$ & 1 & -8 & \\
\hline & Long & -18 & -37 & 14 & 1 & \\
\hline & Short & $-46 * * *$ & $75 * *$ & 14 & $9 * *$ & \\
\hline \multirow[t]{3}{*}{$(8)$} & Fixed Carry & -3 & $-48 * *$ & -11 & 0 & \\
\hline & Long & 2 & -12 & -17 & 0 & \\
\hline & Short & 5 & $35 * *$ & -6 & 0 & \\
\hline \multirow[t]{3}{*}{$(9)$} & Floating Carry & $33 *$ & $-114 * * *$ & -3 & & $-3 *$ \\
\hline & Long & -18 & -35 & 12 & & $-3 *$ \\
\hline & Short & $-51 * * *$ & $80 * * *$ & 16 & & 0 \\
\hline \multirow[t]{3}{*}{ (10) } & Fixed Carry & -3 & $-49 * *$ & -11 & & 0 \\
\hline & Long & 2 & -13 & -17 & & 0 \\
\hline & Short & 5 & $35 * *$ & -6 & & 0 \\
\hline
\end{tabular}


Table IA.8

Floating and Fixed Carry Returns and Exchange Rate Regime Shifts Represented by the Fraction of Fixed (Floating) Pairs Switching to Floating

(Fixed)

Table IA.8 reports the relationship between exchange rate regime shifts and carry trade returns. Using GBP as the reference currency, we regress the monthly spot returns (basis points) for the floating and fixed carry trades on dummy variables indicating fixed-to-floating $\left(P_{\text {Fixed } \rightarrow \text { Float }}\right)$ and floating-to-fixed $\left(P_{\text {Float } \rightarrow \text { Fixed }}\right)$ regime changes in the investment universe, controlling for volatility risks of the U.S. equity market $(\triangle \mathrm{EQV})$ and of floating currency pairs in the foreign exchange market $(\triangle \mathrm{FXV})$. We then repeat this regression for monthly returns of each of the long (Long) and short (Short) legs of the floating and fixed carry trades. Volatility is measured as the exponentially weighted moving average of daily returns and volatility risk is measured as the one-month first difference of volatility. $*$, ** , and *** indicates statistical significance at $10 \%, 5 \%$, and $1 \%$ levels, respectively. The sample runs from Dec. 1919 to Dec. 2017. 
Table IA.8

Floating and Fixed Carry Returns and Exchange Rate Regime Shifts Represented by the Fraction of Fixed (Floating) Pairs Switching to Floating (Fixed) (cont.)

\begin{tabular}{|c|c|c|c|c|c|c|}
\hline & & Constant & $P_{\text {Fixed } \rightarrow \text { Float }}$ & $P_{\text {Float } \rightarrow \text { Fixed }}$ & $\Delta \mathrm{FXV}$ & $\triangle \mathrm{EQV}$ \\
\hline \multirow[t]{3}{*}{$(1)$} & Floating Carry & 22 & $-185 * *$ & -41 & & \\
\hline & Long & -16 & 93 & -37 & & \\
\hline & Short & $-39 * *$ & $278 * * *$ & 4 & & \\
\hline \multirow[t]{3}{*}{$(2)$} & Fixed Carry & -5 & $-138 * * *$ & -28 & & \\
\hline & Long & 0 & -38 & -33 & & \\
\hline & Short & 5 & $101 * * *$ & -5 & & \\
\hline \multirow[t]{3}{*}{$(3)$} & Floating Carry & 3 & & & $-9 *$ & \\
\hline & Long & $-21 *$ & & & 1 & \\
\hline & Short & $-24 *$ & & & $10 * *$ & \\
\hline \multirow{3}{*}{$(4)$} & Fixed Carry & $-19 * *$ & & & -2 & \\
\hline & Long & -7 & & & -1 & \\
\hline & Short & $11 *$ & & & 1 & \\
\hline \multirow[t]{3}{*}{$(5)$} & Floating Carry & 6 & & & & $-3 *$ \\
\hline & Long & $-22 *$ & & & & $-3 *$ \\
\hline & Short & $-27 * *$ & & & & 0 \\
\hline \multirow[t]{3}{*}{$(6)$} & Fixed Carry & $-18 * *$ & & & & 0 \\
\hline & Long & -7 & & & & 0 \\
\hline & Short & $11 *$ & & & & 0 \\
\hline \multirow[t]{3}{*}{$(7)$} & Floating Carry & 19 & $-177 * *$ & -42 & -1 & \\
\hline & Long & -16 & 92 & -37 & 0 & \\
\hline & Short & $-35 * *$ & $270 * * *$ & 5 & $1 *$ & \\
\hline \multirow[t]{3}{*}{$(8)$} & Fixed Carry & -5 & $-137 * * *$ & -28 & -1 & \\
\hline & Long & 0 & -37 & -33 & 0 & \\
\hline & Short & 5 & $100 * * *$ & -5 & 1 & \\
\hline \multirow{3}{*}{ (9) } & Floating Carry & 22 & -179 ** & -42 & & $-3 *$ \\
\hline & Long & -16 & 96 & -38 & & -2 \\
\hline & Short & $-38 * *$ & $275 * * *$ & 4 & & 1 \\
\hline \multirow[t]{3}{*}{ (10) } & Fixed Carry & -5 & -139 *** & -28 & & -1 \\
\hline & Long & 0 & -39 & -33 & & 0 \\
\hline & Short & 5 & $100 * * *$ & -5 & & 1 \\
\hline
\end{tabular}


Table IA.9

\section{The Relationship between Spot Returns after Transaction Costs of Floating} and Fixed Carry Strategies and Regime Shifts.

Table IA.9 reports results for the relationship between regime changes and monthly returns to the carry trade (basis points). We regress the realized spot returns after transaction costs for the floating and fixed carry trades respectively on variables indicating exchange rate regime changes in the investment universe. We model regime changes, both fixed to floating and vice versa, by dummy variables (Panel A) and the fraction of currency pairs experiencing regime shifts (Panel B).*, , **, and $* * *$ indicates statistical significance at 10\%, 5\%, and 1\% levels, respectively. The sample runs from Dec. 1919 to Dec. 2017.

\begin{tabular}{|c|c|c|c|c|c|c|}
\hline \multicolumn{7}{|c|}{ Fixed } \\
\hline & (1) & $(2)$ & (3) & (1) & $(2)$ & (3) \\
\hline \multicolumn{7}{|c|}{ Panel A. Dummy Variables for Regime Changes } \\
\hline CONSTANT & 26 & 0 & 25 & -9 & $-20 * *$ & -7 \\
\hline$D_{\text {Fixed } \rightarrow \text { Float }}$ & $-121 * * *$ & & $-121 * * *$ & $-75 * * *$ & & $-74 * * *$ \\
\hline$D_{\text {Float } \rightarrow \text { Fixed }}$ & & -5 & 2 & & -13 & -6 \\
\hline
\end{tabular}

Panel B. Fraction of Currency Pairs Experiencing Regime Changes

\begin{tabular}{lcccccc}
\hline CONSTANT & 14 & 0 & 17 & -12 & $-24 * * *$ & -11 \\
$P_{\text {Fixed } \rightarrow \text { Float }}$ & $-200 * * *$ & & $-205 * * *$ & $-180 * * *$ & & $-181 * * *$ \\
$P_{\text {Float } \rightarrow \text { Fixed }}$ & & -25 & -49 & & -10 & -27 \\
\hline
\end{tabular}


Table IA.10

The Relationship between Spot Returns after Transaction Costs of Floating and Fixed Carry Strategies and Regime Shifts Using Alternative Regime Shift Indicators

Table IA.10 reports results for the relationship between regime changes and monthly returns to the carry trade (basis points) using modified regime change indicators. We regress the realized spot returns after transaction costs for the floating and fixed carry trades respectively on different definitions of the dummy variables indicating exchange rate regime changes in the investment universe. In Panel A volatility must increase by at least $1 \%$ to qualify for a regime change and in Panel $\mathrm{B}$ by at least $2 \%$. In Panel $\mathrm{C}$, we exclude an extreme carry return outlier for July to August, 1931. Finally, in Panel D, we exclude those months in which both fixed-to-floating and floating-to-fixed regime shifts occur. $*, * *$, and $* * *$ indicates statistical significance at $10 \%, 5 \%$, and $1 \%$ levels, respectively. The sample runs from Dec. 1919 to Dec. 2017.

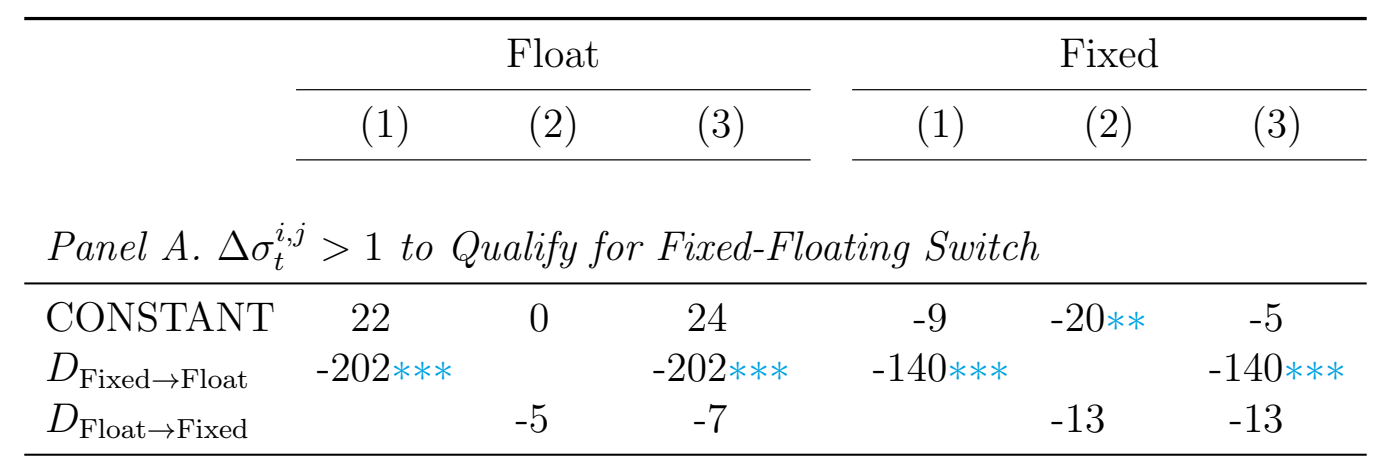

Panel B. $\Delta \sigma_{t}^{i, j}>2$ to Qualify for Fixed-Floating Switch

\begin{tabular}{lcccccc}
\hline CONSTANT & 18 & 0 & 22 & -9 & $-20 * *$ & -5 \\
$D_{\text {Fixed } \rightarrow \text { Float }}$ & $-240 * * *$ & & $-241 * * *$ & $-179 * * *$ & & $-180 * * *$ \\
$D_{\text {Float } \rightarrow \text { Fixed }}$ & & -5 & -11 & & -13 & -16 \\
\hline
\end{tabular}

Panel C. Excluding the Return from June 1931 to July 1931

\begin{tabular}{|c|c|c|c|c|c|c|}
\hline $\begin{array}{l}\text { CONSTANT } \\
D_{\text {Fixed } \rightarrow \text { Float }} \\
D_{\text {Float } \rightarrow \text { Fixed }}\end{array}$ & $\begin{array}{c}26 * * \\
-100 * * *\end{array}$ & -12 & $\begin{array}{c}28 \\
-100 * * * \\
-7\end{array}$ & $\begin{array}{c}-9 \\
-75 * * *\end{array}$ & $-20 * *$ & $\begin{array}{c}-8 \\
-75 * * * \\
-6\end{array}$ \\
\hline \multicolumn{7}{|c|}{ Panel D: Excluding the Months in Which Both Regime Shifts Occur } \\
\hline CONSTANT & 26 & 0 & $36 *$ & -9 & $-20 * * *$ & -3 \\
\hline$D_{\text {Fixed } \rightarrow \text { Float }}$ & $-165 * * *$ & & $-175 * * *$ & $-96 * *$ & & $-103 * * *$ \\
\hline$D_{\text {Float } \rightarrow \text { Fixed }}$ & & 5 & -31 & & -7 & -25 \\
\hline
\end{tabular}


Table IA.11

The Relationship between Spot Returns after Transaction Costs of Floating and Fixed Carry Strategies and Regime Shifts When the Period of 1939 to 1958 is Excluded

Table IA.11 reports results for the relationship between regime changes and monthly returns to the carry trade (basis points) when the period 1939-1958 is excluded from the sample. We regress the realized spot returns after transaction costs for the floating and fixed carry trades respectively on variables indicating exchange rate regime changes in the investment universe. We model regime changes, both fixed to floating and vice versa, by dummy variables (Panel A) and the fraction of currency pairs experiencing regime shifts (Panel B). * , **, and *** indicates statistical significance at 10\%,5\%, and 1\% levels, respectively. The sample runs from December 1919 to December, 2017, excluding the period from Aug. 1939 to Dec. 1958.

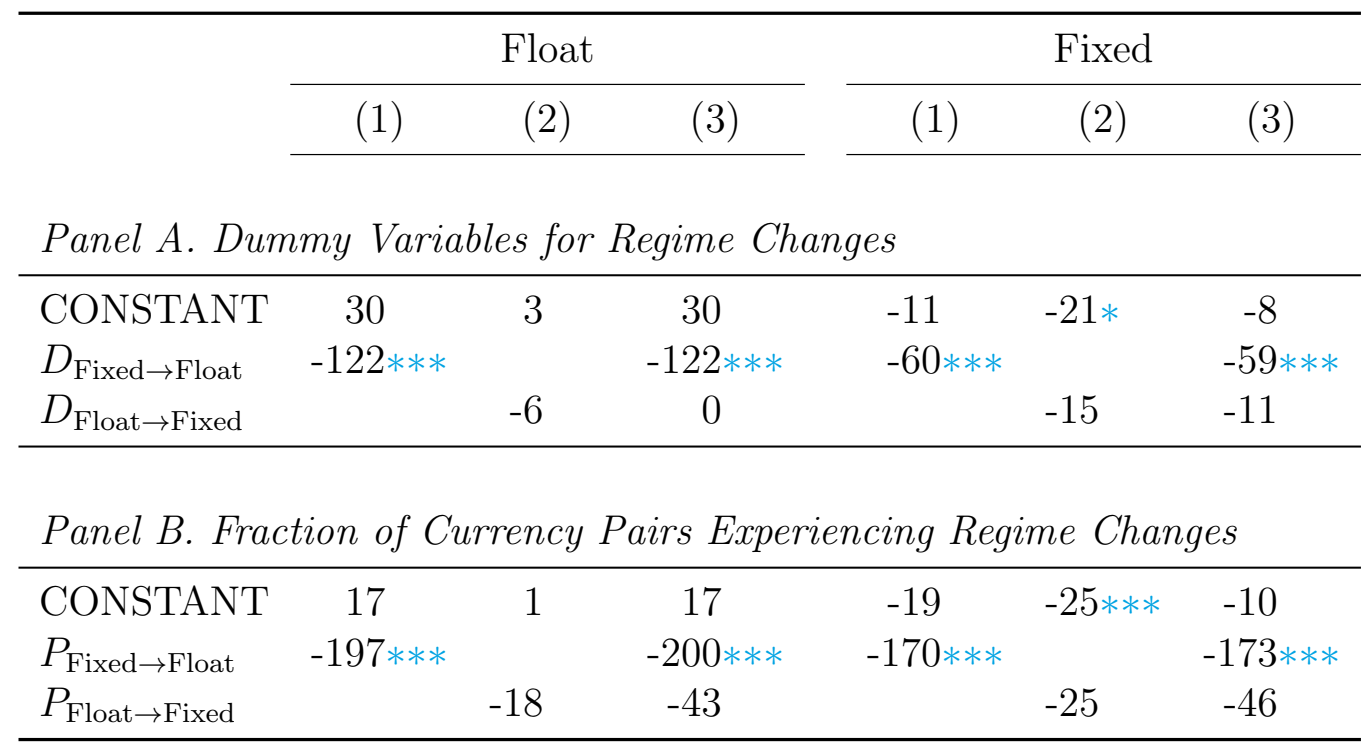


Table IA.12

Fixed-to-Floating Regime Changes Associated with the Largest Monthly Losses of the Floating Carry Trade

Table IA.12 reports the 25 monthly losses to the floating carry trade associated with a fixed-to-floating regime shift. All but five of these 25 months coincide with events that shaped the history of the international financial system and of exchange rate regimes as documented in the secondary sources (Eichengreen (1996), Aldcroft and Oliver (1998), James (2012), and Reinhart and Rogoff (2011)).

\begin{tabular}{|c|c|c|c|}
\hline $\begin{array}{c}\text { Month } \\
t+1\end{array}$ & $\begin{array}{l}\text { Return } \\
\text { (bp) }\end{array}$ & $\begin{array}{c}\text { Example of } \\
\text { collapsed pegs }\end{array}$ & Main Historical Event \\
\hline $1931 \mathrm{~m} 07$ & -4490 & $\mathrm{DEM} / \mathrm{USD}$ & The collapse of the gold standard system in the 1930s: July 1931 German Crisis \\
\hline $1977 \mathrm{~m} 07$ & -1415 & $\mathrm{ESP} / \mathrm{FRF}$ & \\
\hline $1922 \mathrm{~m} 11$ & -1098 & $\mathrm{CHF} / \mathrm{USD}$ & Pressure on $\mathrm{CHF}$, followed by a referendum on the introduction of a capital levy \\
\hline $1926 \mathrm{~m} 04$ & -988 & $\mathrm{ESP} / \mathrm{DEM}$ & Speculation on ESP in the hope of stablization at the prewar gold parity \\
\hline $1926 \mathrm{~m} 05$ & -987 & $\mathrm{ESP} / \mathrm{USD}$ & Speculation on ESP in the hope of stablization at the prewar gold parity \\
\hline $1939 \mathrm{~m} 09$ & -965 & $\mathrm{BEF} / \mathrm{USD}$ & The collapse of the managed floating regimes in Europe at the outbreak of WWII \\
\hline $1993 \mathrm{~m} 07$ & -957 & $\mathrm{BEF} / \mathrm{DEM}$ & The European Monetary System crisis of 1992-1993: the widening ERM band \\
\hline $1995 \mathrm{~m} 03$ & -901 & PTE/DEM & Spain and Portugal exchange rate realignment \\
\hline $1987 \mathrm{~m} 10$ & -865 & $\mathrm{ESP} / \mathrm{NLG}$ & 1987 Stock Market Crash spill-over to the foreign exchange markets \\
\hline $1935 \mathrm{~m} 03$ & -759 & $\mathrm{BEF} / \mathrm{FRF}$ & Belgium suspended the gold standard \\
\hline $1977 \mathrm{~m} 08$ & -739 & $\mathrm{FRF} / \mathrm{USD}$ & Sweden suspended agreement with Snake: DEM/SEK volatility increased from $7 \%$ to $21 \%$ \\
\hline $2008 \mathrm{~m} 09$ & -739 & $\mathrm{SEK} / \mathrm{EUR}$ & Nadir of the 2008 GFC (The bankruptcy of Lehman Brothers) \\
\hline $2007 \mathrm{~m} 08$ & -721 & $\mathrm{CHF} / \mathrm{EUR}$ & SNB and ECB responded to money market tension at the beginning of the GFC \\
\hline $1924 \mathrm{~m} 07$ & -720 & $\mathrm{CHF} / \mathrm{USD}$ & CHF and GBP started appreciating against USD before returning to the gold standard \\
\hline $1992 \mathrm{~m} 09$ & -628 & $\mathrm{GBP} / \mathrm{DEM}$ & The European Monetary System crisis of 1992-1993: Black Wednesday \\
\hline $1933 \mathrm{~m} 04$ & -607 & USD/FRF & The collapse of the gold standard in the 1930s: the US April 1933 devaluation \\
\hline $1989 \mathrm{~m} 02$ & -599 & ITL/CHF & \\
\hline $2010 \mathrm{~m} 05$ & -566 & $\mathrm{CHF} / \mathrm{EUR}$ & The climax of the European debt crisis: Greece asked for financial support from IMF \\
\hline $1980 \mathrm{~m} 04$ & -531 & NOK/SEK & \\
\hline $2015 \mathrm{~m} 01$ & -519 & $\mathrm{CHF} / \mathrm{EUR}$ & SNB abandoned euro cap \\
\hline $1973 \mathrm{~m} 06$ & -515 & DEM/NLG & Snake realignment: DEM revalued by $5.5 \%$ \\
\hline $1976 \mathrm{~m} 04$ & -496 & ATS/NOK & - \\
\hline $2007 \mathrm{~m} 11$ & -494 & $\mathrm{CHF} / \mathrm{EUR}$ & SNB,ECB, FED introduced swap lines following dollar liquidity shortages among EU banks \\
\hline $1992 \mathrm{~m} 01$ & -470 & ATS/BEF & - \\
\hline $1976 \mathrm{~m} 03$ & -457 & FRF/DEM & France withdrew from Snake again following its first withdrawal in Jan 1974 \\
\hline
\end{tabular}




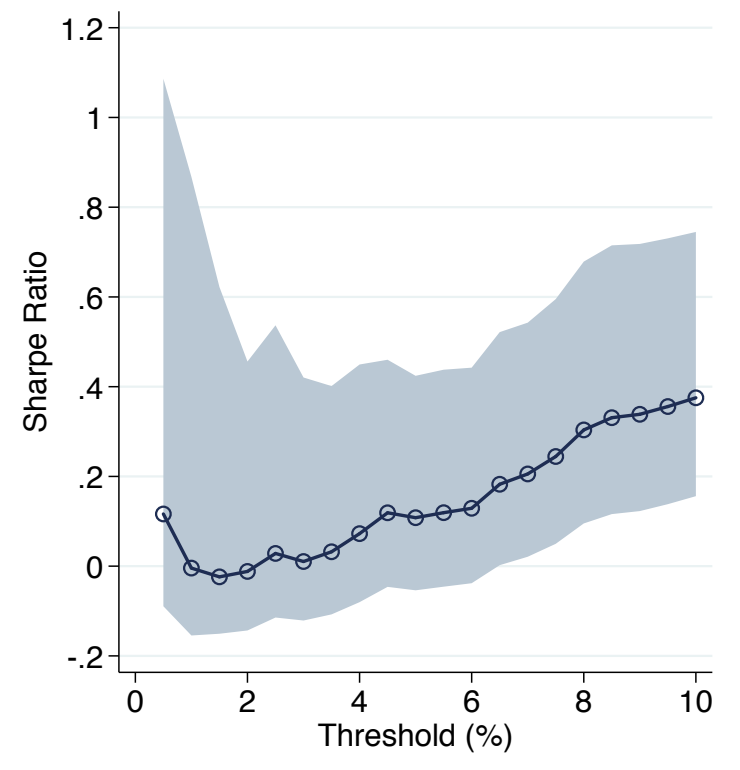

(a) Fixed regime, before transaction costs

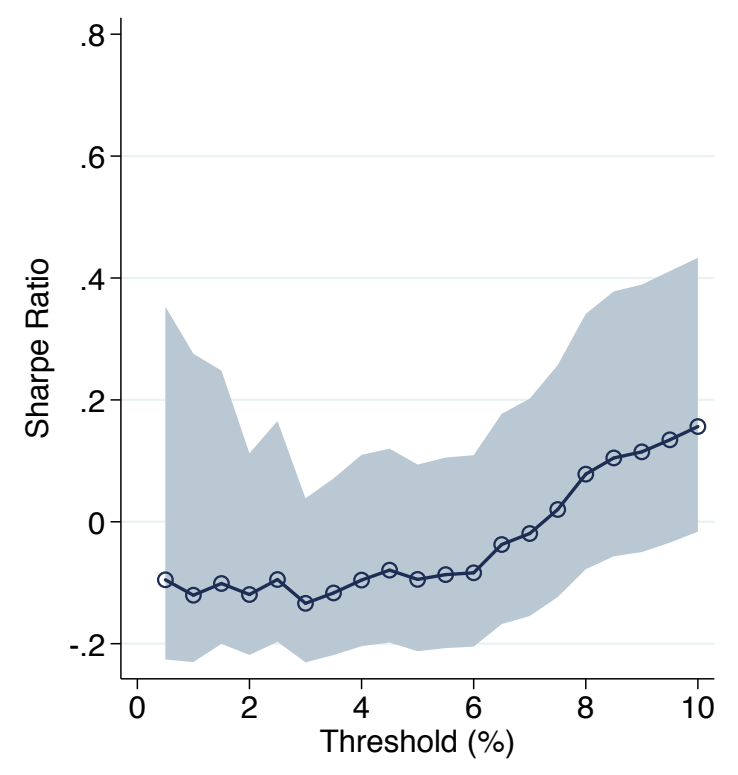

(c) Fixed regime, after transaction costs

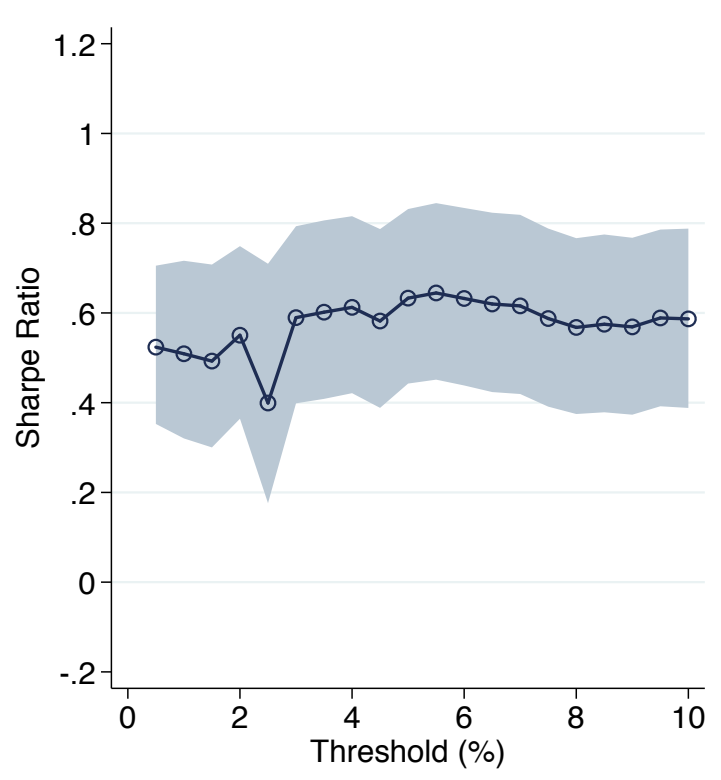

(b) Floating regime, before transaction costs

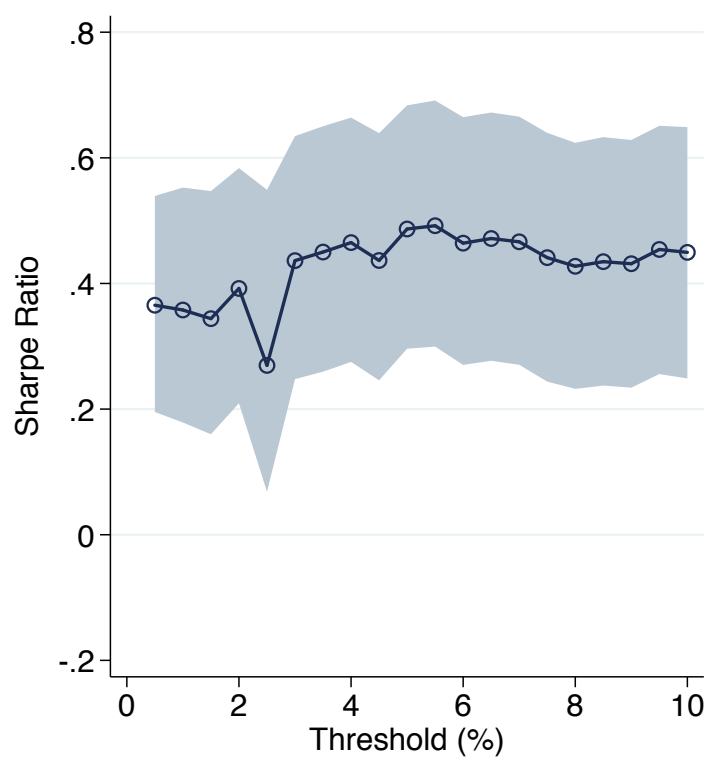

(d) Floating regime, after transaction costs

Figure IA.1. Sharpe Ratios of Fixed and Floating Carry Trades across Different Volatility Thresholds. Figure IA.1 summarizes the Sharpe ratios (including the 5th and the 95th percentiles), before and after transaction costs, corresponding to the fixed regime (graphs (a) and (b)) and floating regime (graphs (c) and (d)) respectively, using a range of volatility thresholds to classify exchange rate regimes over the period Dec. 1919 to Dec. 2017. 